\title{
Polymer microsphere-assisted synthesis of lithium-rich cathode with improved
}

\section{electrochemical performance ${ }^{l}$}

Shaomeng Ma ${ }^{\mathrm{a}}$, Xianhua Hou, ${ }^{\mathrm{a}, \mathrm{b}, *}$, Yanling Huang ${ }^{\mathrm{a}}$, Changming $\mathrm{Li}^{\mathrm{c}}$, Shejun $\mathrm{Hu}^{\mathrm{a}, \mathrm{b}}$,

$$
\text { Kwok-ho Lam }{ }^{\text {d* }}
$$

${ }^{\mathrm{a}}$ Guangdong Provincial Key Laboratory of Quantum Engineering and Quantum Materials, School of Physics and Telecommunication Engineering, South China Normal University, Guangzhou 510006,

\section{China}

${ }^{\mathrm{b}}$ Guangdong Provincial Engineering Research Center for Optoelectronic Instrument, Guangzhou 510006, China

${ }^{\mathrm{c}}$ School of Mechanical and Electrical Engineering, Wuyi University, Jiangmen 529020, PR China

${ }^{\mathrm{d} D e p a r t m e n t}$ of Electrical Engineering, The Hong Kong Polytechnic University, Hunghom, Kowloon, Hong Kong

\begin{abstract}
The Li-rich layered cathode material $\mathrm{Li}_{1.165} \mathrm{Mn}_{0.501} \mathrm{Ni}_{0.167} \mathrm{Co}_{0.167} \mathrm{O}_{2}$ with porous structure has been successfully synthesized through a facile co-precipitation approach followed with a high-temperature calcination treatment, adopting polymer microsphere (PSA) as a template and conductive agent. The PSA-assisted $\mathrm{Li}_{1.165} \mathrm{Mn}_{0.501} \mathrm{Ni}_{0.167} \mathrm{Co}_{0.167} \mathrm{O}_{2}$ composite exhibits remarkably improved cycling stability and rate capability compared with the bare composite. It delivers a high initial discharge capacity of $267.0 \mathrm{~mA} \mathrm{~h} \mathrm{~g}^{-1}$ at $0.1 \mathrm{C}\left(1 \mathrm{C}=250 \mathrm{~mA} \mathrm{~g}^{-1}\right)$ between $2.0 \mathrm{~V}$ and $4.65 \mathrm{~V}$. A
\end{abstract}

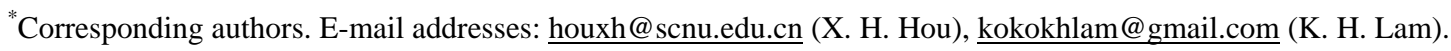


discharge capacity of $214.9 \mathrm{~mA} \mathrm{~h} \mathrm{~g}^{-1}$ is still obtained after 100 cycles. Furthermore, the diffusion coefficients of $\mathrm{Li}^{+}$investigated by the cyclic voltammetry technique are approximately $10^{-15}-10^{-14} \mathrm{~cm}^{2} \mathrm{~s}^{-1}$. Such outstanding performance is mainly ascribed to: on one hand, the carbon residue of PSA after being calcined at high temperature contributes to enhance the electronic conductivity of the electrode and alleviates the volume changes during the $\mathrm{Li}^{+}$-insertion/extraction, leading to an improved rate capability; on the other hand, the unique porous structure and small particle size are conductive to increase the exposed electrochemical active surface, shorten $\mathrm{Li}^{+}$diffusion distance and thus enhance the lithium storage capacity.

Keywords: Li-rich cathode; co-precipitation; polymer microsphere-assisted; porous structure

\section{Introduction}

In recent years, rechargeable lithium ion batteries (LIBs) have attracted much attention due to their high energy density, long cycle life, high safety and environmental benignity [1-3], which have widely been used in electric vehicles (EVs), plug-in hybrid electric vehicles (PHEVs), and some portable electronic devices [4-10]. It is well known that the cathode material plays an important role in directly determining the battery capacity, cyclability and energy density of electrodes. However, traditional cathode materials, such as $\mathrm{LiCoO}_{2}, \mathrm{LiNiO}_{2}, \mathrm{LiMn}_{2} \mathrm{O}_{4}$ and $\mathrm{LiFePO}_{4}$, usually deliver low discharge capacity, which seriously limit further development and applications of LIBs. Hence, much research attention has been focused on the development of novel and 
advanced cathode materials with high capacity and high safety that are indispensable and urgent to meet the demand for high-performance LIBs [11-13].

The Li-rich layered transition metal oxides $\mathrm{Li}_{1+x}[\mathrm{M}]_{1-x} \mathrm{O}_{2}$ denoted by $x \mathrm{Li}_{2} \mathrm{MnO}_{3} \cdot(1-x) \mathrm{LiMO}_{2}(\mathrm{M}=\mathrm{Mn}, \mathrm{Ni}, \mathrm{Co}$, ect. $)$ are believed to be the most promising and attractive candidate for the next generation cathode because of their markedly high specific capacity of $>250 \mathrm{~mA} \mathrm{~h} \mathrm{~g}{ }^{-1}$ compared to the aforementioned conventional cathodes [14-18]. Such high specific capacity may be ascribed to the oxidation/reduction of transition metal ions in the $\mathrm{LiMO}_{2}$ component and the electrochemical activation of the $\mathrm{Li}_{2} \mathrm{MnO}_{3}$ component accompanying the irreversible loss of oxygen from the lattice. This kind of cathode material is usually considered as a solid solution with an integrated structure of monoclinic $\mathrm{Li}_{2} \mathrm{MnO}_{3}$ (space group $C 2 / m$ ) and rhombohedral $\mathrm{LiMO}_{2}$ (space group $R-3 m$ ) [19-22]. The $\mathrm{Li}_{2} \mathrm{MnO}_{3}$ component is beneficial to stabilize the layered-layered structure, which could offer more efficient ion transport pathway. Nevertheless, the Li-rich materials suffer from some substantial drawbacks, such as poor rate capability, low initial coulombic efficiency and poor cyclability $[23,24]$, which are mainly attributed to the inferior electronic conductivity, phase transformation during $\mathrm{Li}^{+}$-extraction/insertion, side reactions with electrolyte at high operating voltages, and so on [25]. Therefore, the practical utilization of LIBs in the electric automotive commercial market would be restrained seriously.

Great efforts have been devoted to optimizing and improving the electrochemical performance of cathode materials. One of the common strategies is surface modification with some coating materials like carbon materials [26,27], oxides [25], phosphates [28], 
and fluorides [29]. Actually, surface modification functioning as a protection layer do not only effectively suppress the solid electrolyte interface (SEI) layer growth and the dissolution of the surface transition metal ions, but also obviously reduce the contact between active materials and electrolyte, thereby enhancing the surface electronic conductivity and accelerating the surface ion diffusion. Besides, other methods such as ion doping [30], morphological and grain size controlling have also been employed to synthesize and optimize the cathodes. For example, Bohang Song et al. [31] synthesized high-performance cathode material $\mathrm{Li}\left(\mathrm{Li}_{0.2} \mathrm{Mn}_{0.54} \mathrm{Ni}_{0.13} \mathrm{Co}_{0.13}\right) \mathrm{O}_{2}$ by adopting grapheme oxide (GO) surface modification, leading to a significant improvement in rate capability and cycle performance. Qi Li et al. [32] successfully prepared in situ $\mathrm{K}^{+}$-doped $\mathrm{Li}_{1.20} \mathrm{Mn}_{0.54} \mathrm{Ni}_{0.13} \mathrm{Co}_{0.13} \mathrm{O}_{2}$ using potassium containing $\alpha-\mathrm{MnO}_{2}$ as the starting material, which exhibited a superior cycling stability with $85 \%$ of initial capacity $\left(315 \mathrm{~mA} \mathrm{~h} \mathrm{~g}^{-1}\right.$ ) even after 110 cycles.

Aiming at achieving a long-cycle high-rate performance cathode for LIBs, PSA-assisted $\mathrm{Li}_{1.165} \mathrm{Mn}_{0.501} \mathrm{Ni}_{0.167} \mathrm{Co}_{0.167} \mathrm{O}_{2}$ materials with a porous structure were successfully synthesized by co-precipitation method and high-temperature calcination process. Herein, we employed PSA (polymer microsphere) as a template and conductive agent in the preparation process of transition metal carbonate precursor. It is worth noting that the PSA would be carbonized with drastic loss in an oxygen atmosphere during high temperature calcination process. Fortunately, the decomposition product of PSA is helpful to enhance the electronic conductivity and accommodate the volume changes. Furthermore, the unique porous structure and small particle size endow the 
composite shortened $\mathrm{Li}^{+}$transport length and improved specific capacity. Compared with the bare $\mathrm{LMNCO}$ electrode, the PSA-assisted $\mathrm{Li}_{1.165} \mathrm{Mn}_{0.501} \mathrm{Ni}_{0.167} \mathrm{Co}_{0.167} \mathrm{O}_{2}$ exhibits excellent cycling stability (214.9 $\mathrm{mA} \mathrm{h} \mathrm{g}^{-1}$ after 100 cycles) and outstanding rate capability (64.3 $\mathrm{mA} \mathrm{h} \mathrm{g}^{-1}$ at $\left.10 \mathrm{C}\right)$.

\section{Experimental}

\subsection{Materials preparation}

All chemicals (Sigma Aldrich) except for PSA (polymer microsphere) in this experiment were of commercially available analytical purity grade and were used without further purification. The Li-rich $\mathrm{Li}_{1.165} \mathrm{Mn}_{0.501} \mathrm{Ni}_{0.167} \mathrm{Co}_{0.167} \mathrm{O}_{2}$ cathode materials were synthesized via a simple co-precipitation method and subsequent high-temperature calcination as illustrated in Scheme 1. 1.0 M metal acetate salt solutions of $\mathrm{Mn}\left(\mathrm{CH}_{3} \mathrm{COO}\right)_{2} \cdot 4 \mathrm{H}_{2} \mathrm{O}, \mathrm{Ni}\left(\mathrm{CH}_{3} \mathrm{COO}\right)_{2} \cdot 4 \mathrm{H}_{2} \mathrm{O}$, and $\mathrm{Co}\left(\mathrm{CH}_{3} \mathrm{COO}\right)_{2} \cdot 4 \mathrm{H}_{2} \mathrm{O}$ with a molar ratio $\mathrm{Mn}: \mathrm{Ni}:$ Co of $0.501: 0.167: 0.167$ were completely dissolved in deionized water in a continuous stirred reactor. Then, $1.0 \mathrm{~g}$ PSA (33.64\% solid content) was dropped slowly into the above reactor to ensure the uniform distribution of PSA. After stirring for $1 \mathrm{~h}, 1.0 \mathrm{M} \mathrm{Na}_{2} \mathrm{CO}_{3}$ solution was dropped slowly to form uniform carbonate precipitation. The mixed solution was subjected to a slight alkali environment with a $\mathrm{pH}$ value of $\sim 8.0$ by adding a desired amount of ammonium hydroxide solution. After continuously stirring for $6 \mathrm{~h}$, the resultant precipitates were filtered and washed thoroughly with deionized water, and then dried at $60{ }^{\circ} \mathrm{C}$ overnight in a vacuum oven. It should be noted that in the mixing process, the PSA could be embedded in the transition 
metal carbonate $\mathrm{MCO}_{3}(\mathrm{M}=\mathrm{Mn}$, Ni, Co, etc. $)$ matrix. Afterwards, the obtained precursor was thoroughly ground and mixed with $\mathrm{Li}_{2} \mathrm{CO}_{3}$ in a stoichiometric amount. The mixture was then preheated at $500{ }^{\circ} \mathrm{C}$ for $5 \mathrm{~h}$ and subsequently calcined at $900{ }^{\circ} \mathrm{C}$ for $12 \mathrm{~h}$ in air. The resultant product was cooled down to room temperature and ground into powders for the electrode fabrication. The as-prepared product was named as

\section{LMNCO/PSA.}

For comparison, a sample named bare LMNCO was prepared by an analogous route as the abovementioned preparation method of the sample LMNCO/PSA. The only difference is without adding PSA.

Herein, the preparation method of PSA is briefly introduced as follows. The material was successfully synthesized by a semi-continuous emulsion polymerization method. In this work, acrylonitrile (AN) was used as the main monomer, a small amount of styrene (St) as the comonomer, polyvinyl alcohol (PVA) as the protective colloid, water as the main dispersing medium, the organic alcohol $\mathrm{K}_{2} \mathrm{~S}_{2} \mathrm{O}_{8}$ as the initiating system. The as-prepared polymer particles named PSA are a kind of polymer microspheres with the main component of polyacrylonitrile that is composed of $\mathrm{C}, \mathrm{H}$ and $\mathrm{N}$ elements.

\subsection{Structural characterization}

The crystalline structures of the as-prepared products were characterized by X-ray diffraction (XRD; PANalytical X'Pert PRO, $\mathrm{Cu} \mathrm{K} \alpha$ radiation, $\lambda=0.15406 \mathrm{~nm}$ ) and the $\mathrm{XRD}$ data was collected in a $2 \theta$ range of $10^{\circ}-80^{\circ}$ at a scan rate of $5^{\circ} \mathrm{min}^{-1}$. The particle morphology and microstructure of the as-prepared products were assessed by scanning electron microscopy (SEM; ZEISS ULTRA 55) and transmission electron microscopy 
(TEM; JEM-2100HR). Raman spectroscopy of the precursor was measured by HR800UV Raman microspectrometer (Jobin Yvon; France) with a $514.53 \mathrm{~nm}$ argon laser as an excitation source. The Fourier transform infrared spectroscopy (FT-IR, Nicolet 380 spectrometer) of the precursor was analyzed within the $4000-650 \mathrm{~cm}^{-1}$ range. To determine the exact decomposition temperature of PSA, thermogravimetric analysis (TG, Nezsch Sta 409) was conducted in air between $37.5^{\circ} \mathrm{C}$ and $700{ }^{\circ} \mathrm{C}$ with a heating rate of $10^{\circ} \mathrm{C} \mathrm{min}^{-1}$.

\subsection{Electrochemical measurements}

The electrochemical measurements were performed using coin-type half-cells (CR2430) assembled in an argon-filled glove box. The working electrodes were made by coating a mixture with the composition of 80 wt. $\%$ active materials, 10 wt. $\%$ Super-P (conductive agent) and 10 wt.\% PVDF (the binder) on aluminum foil. Then, the electrodes were dried at $60{ }^{\circ} \mathrm{C}$ overnight in vacuum and subsequently pressed and punched into disks with a diameter of $18 \mathrm{~mm}$. The average loading mass of the active material for the electrodes was approximately $5.92 \mathrm{mg}$. $1.0 \mathrm{M} \mathrm{LiPF}_{6}$ dissolved in a mixture of ethylene carbonate (EC), diethyl carbonate (DEC) and ethylene methyl carbonate (EMC) (1:1:1 in volume, provided by Chei Industries Inc., South Korea) was used as the electrolyte. The metallic lithium foil was served as the counter and reference electrodes. A polypropylene micro-porous film (Cellgard 2400) was used as the separator.

The charge-discharge tests were galvanostatically performed using a LAND CT2001A battery program-control testing system at the current densities of 25-2500 
$\mathrm{mA} \mathrm{g}^{-1}\left(1 \mathrm{C}=250 \mathrm{~mA} \mathrm{~g}^{-1}\right)$ between $2.0 \mathrm{~V}$ and $4.65 \mathrm{~V}$ at $25^{\circ} \mathrm{C}$. Cyclic voltammograms (CV) were carried out using a Solartron Analytical 1470E electrochemical system in the potential window of 2.5-4.65 V. Electrochemical impedance spectroscopy (EIS) was conducted under a frequency range from $100 \mathrm{kHz}$ to $0.01 \mathrm{~Hz}$. The potentials in this work refer to the $\mathrm{Li} / \mathrm{Li}^{+}$couple.

\section{Results and discussions}

\subsection{Structural and morphological characterization}

In order to investigate the thermal decomposition process of PSA and provide the basis for later analysis, thermogravimetric (TG) test of PSA was conducted in air with a heating rate of $10{ }^{\circ} \mathrm{C} \min ^{-1}$ between $37.5^{\circ} \mathrm{C}$ and $700{ }^{\circ} \mathrm{C}$. The TG curve of PSA is shown in Fig. 1. There is no obvious weight loss $(5.10 \mathrm{wt} . \%)$ during heating below $300{ }^{\circ} \mathrm{C}$, which can be ascribed to the evaporation of residual water. However, a drastic weight loss took place between $300{ }^{\circ} \mathrm{C}$ and $400{ }^{\circ} \mathrm{C}$ with only 44.56 wt. $\%$ weight retention, which can be attributed to the loss of internal crystal water. The drastic weight loss between $470{ }^{\circ} \mathrm{C}$ and $620{ }^{\circ} \mathrm{C}$ is considered as the result from the decomposition of carbon containing functional groups. Afterwards, the weight retention reaches to a steady value of nearly 0.05 wt.\%. The result shows that a slight amount of carbon residue still can be remained after high temperature calcination, which is believed to conduce to the enhancement of electronic conductivity and alleviation of volume change.

The XRD patterns of the precursors as shown in Fig. 2a can be well indexed as a 
typical hexagonal structure with $R-3 c$ space group, which correspond to the standard power diffraction cards of $\mathrm{MnCO}_{3}(\mathrm{PDF} 444-1472), \mathrm{NiCO}_{3}(\mathrm{PDF} \# 12-0771)$ and $\mathrm{CoCO}_{3}$ (PDF\#11-0692), suggesting the formation of carbonate. There is no obvious difference detected from both XRD patterns. Fig. $2 b$ shows the XRD patterns of the bare LMNCO and LMNCO/PSA materials after high temperature calcination. The main diffraction peaks present a hexagonal $\alpha-\mathrm{NaFeO}_{2}$ layered structure with $R-3 m$ space group, expect for the low intensity reflections between $20^{\circ}$ and $25^{\circ}$ [33-35]. The weak superlattice peaks between $20^{\circ}$ and $25^{\circ}$, which are marked with dash dot lines, correspond to the monoclinic $\mathrm{Li}_{2} \mathrm{MnO}_{3}$ phase with $C 2 / m$ space group deriving from the unique $\mathrm{LiMn}_{6}$ ordering of the transition metal in the 3a site [36]. The distinct split peaks of $(006) /(102)$ and (108)/(110) are the characteristic of a well-formed layered structure [37]. Besides, no impurity phase is detected from the XRD patterns, indicating the high purity of the oxides. As can be seen from Fig. 2b, the XRD patterns of the LMNCO/PSA are almost identical to that of the bare $\mathrm{LMNCO}$ except for the regions between $20^{\circ}$ and $25^{\circ}$, where the peak intensity of the LMNCO/PSA is comparatively weaker. This indicates that the main structure of LMNCO material remains unchanged despite of adopting PSA in the preparation process. Whereas, such difference between $20^{\circ}$ and $25^{\circ}$ may be attributed to the influence of the decomposition products of PSA $\left(\mathrm{C}, \mathrm{N}\right.$, etc.) on $\mathrm{Li}_{2} \mathrm{MnO}_{3}$, which similarly contributes the stabilization of the layered structure so as to enhance the electronic conductivity and improve the electrochemical performance.

Because of the similar XRD patterns of both precursors, the precursors were also characterized by Raman spectroscopy to monitor the structural change in the region of 
300-1800 $\mathrm{cm}^{-1}$. As observed from Fig. 3a, wide Raman spectra in the spectral range of $500-610 \mathrm{~cm}^{-1}$ composed of some small peaks can be observed that can be attributed to the Raman-active $\mathrm{A}_{1 \mathrm{~g}}\left(\mathrm{M}-\mathrm{O}\right.$ symmetrical stretching) and $\mathrm{E}_{\mathrm{g}}$ (symmetrical deformation) modes [38]. In addition, the Raman spectrum of the precursor of LMNCO/PSA composite is distinguishable from that of the bare LMNCO due to adopting the PSA, mainly reflecting in the absorption peak at $1000 \mathrm{~cm}^{-1}$ and the regions of $1300-1620$ $\mathrm{cm}^{-1}$. The peak at $1000 \mathrm{~cm}^{-1}$ is a sign of amorphous carbon. The weak D band around $1325 \mathrm{~cm}^{-1}$ is a breathing mode of $\mathrm{k}$-point phonons of $\mathrm{A}_{1 \mathrm{~g}}$ symmetry corresponding to $\mathrm{sp}^{3}$ carbon atoms, which derives from structural defects and disorder of carbon [39]. The strong $\mathrm{G}$ band around $1600 \mathrm{~cm}^{-1}$ is associated with the in-plane stretching vibration of the $\mathrm{E}_{2 \mathrm{~g}}$ phonon of $\mathrm{sp}^{2}$ carbon atoms $[39,40]$. Hence, the peak intensity ratio of $\mathrm{D}$ band to $\mathrm{G}$ band $\left(I_{\mathrm{D}} / I_{\mathrm{G}}\right)$ can indicate the degree of lattice defects and structural disorder. The observation is accordant with the Raman spectrum of PSA as shown in the inset, indicating that the PSA has an influence on the structure of the transition metal carbonate precursor. Here, the intensity ratio $I_{\mathrm{D}} / I_{\mathrm{G}}$ is calculated to be a smaller value $\sim 0.72$, indicating lower density of lattice defects and disorder level, which could facilitate the $\mathrm{Li}^{+}$and electron transportation. Additionally, a distinct peak located at $1450 \mathrm{~cm}^{-1}$ is observed, which is considered to be the synergetic effect between PSA and transition metal carbonate.

FT-IR spectra (Fig. 3b) of the precursors were also measured to identify the functional groups or chemical bonds, confirm the presence of PSA and investigate the interaction between PSA and LMNCO particles. The strong and wide absorption band at 
$3300 \mathrm{~cm}^{-1}$ is assigned to $\mathrm{C}-\mathrm{H}$ stretching vibration. The bands at $2935 \mathrm{~cm}^{-1}, 1453 \mathrm{~cm}^{-1}$ and $1090 \mathrm{~cm}^{-1}$ are attributed to $-\mathrm{CH}_{2}$ stretching vibration, $-\mathrm{CH}_{2}$ bending vibration and $\mathrm{C}-\mathrm{C}$ skeletal vibration, respectively. The acute band at $2241 \mathrm{~cm}^{-1}$ corresponds to $\mathrm{C} \equiv \mathrm{N}$ stretching vibration [41], which is the characteristic band of acrylonitrile (AN). More importantly, the $\mathrm{C} \equiv \mathrm{N}$ band is considered to be capable of stabilizing the structure and enhancing cycling stability. The weak band at $1603 \mathrm{~cm}^{-1}$ is related to $\mathrm{C}=\mathrm{N}, \mathrm{C}=\mathrm{C}$ and $\mathrm{N}-\mathrm{H}$ stretching vibration. As compared with the bare LMNCO, two wide absorption peaks of the LMNCO/PSA are shifted to higher wavenumbers $\left(3270 \mathrm{~cm}^{-1} \rightarrow 3340 \mathrm{~cm}^{-1}\right.$, $1367 \mathrm{~cm}^{-1} \rightarrow 1373 \mathrm{~cm}^{-1}$ ) and the intensity of the weak band at $2935 \mathrm{~cm}^{-1}$ is strengthened slightly, which can be attributed to the special interaction between PSA and the transition metal carbonate. The characteristic bands at $2241 \mathrm{~cm}^{-1}, 762 \mathrm{~cm}^{-1}$ and $703 \mathrm{~cm}^{-1}$ observed in the PSA are also detectable in the FT-IR spectrum of the precursor of the LMNCO/PSA, implying the presence of PSA.

The morphologies of the precursors and composites were investigated in detail by SEM. The precursor of the bare LMNCO (Fig. 4a) shows a spherical shape of 1.8-2.4 $\mu \mathrm{m}$ in diameter with smooth surface. Meanwhile, the bare LMNCO composite retains the sphere morphology with sharp edges as shown in Fig. 4c. The secondary particles possess a diameter of 1.6-2.0 $\mu \mathrm{m}$, which are composed of the primary particles (200-400 nm). As expected, for the precursor of the LMNCO/PSA (Fig. 4b), transition metal carbonate and PSA are reunited together to form a spherical shape with rough surface and small particle size of $0.8-1.5 \mu \mathrm{m}$. The LMNCO/PSA composite was obtained after calcined at high temperature in an oxygen atmosphere, which could lead 
to the carbonization of PSA with drastic weight loss and induce many pores and canals, resulting in the rearrangement of particles and the formation of the unique porous structure. As shown in Fig. 4d, the final product LMNCO/PSA presents a spherical morphology. The size of the secondary particles is smaller with a diameter of $1.0-1.5$ $\mu \mathrm{m}$, and the primary particles also own smaller size of 100-200 nm. Fig. 4e shows the SEM image of PSA, indicating a kind of polymer microsphere with a diameter range of 200-400 nm, which agrees well with the observation from the inset in Fig. 4b. To make a direct observation on the internal structure of the material, the SEM image of the cross-section of the LMNCO/PSA particles is presented in Fig. 4f. The LMNCO/PSA material displays an aggregated sphere with a porous structure in cross section, which is mainly attributed to the carbonization of PSA after high temperature calcinations and the stabilizing effect of the decomposition product structure. It is recognized that the sample LMNCO/PSA with smaller size and porous structure is conductive so as to increase the exposed surface for more $\mathrm{Li}^{+}$-extraction/insertion channels and shorten paths for fast $\mathrm{Li}^{+}$-diffusion, resulting in the improvement of cycling performance $[3,42]$.

In order to further investigate the microstructures of the LMNCO/PSA and bare LMNCO, transmission electron microscopy (TEM) measurement was carried out and the results are shown in Fig. 5. As clearly seen from the TEM images, a lattice fringe of $d=0.244 \mathrm{~nm}$ can be calculated, which corresponds to (101) plane of rhombohedral $\mathrm{LiMO}_{2}$. Meanwhile, the lattice fringe with an interplanar spacing between two adjacent lattice fringes of $0.47 \mathrm{~nm}$ comes from the (003) plane of rhombohedral $\mathrm{LiMO}_{2}(R-3 m)$ and/or monoclinic $\mathrm{Li}_{2} \mathrm{MnO}_{3}(C 2 / m)$. In addition, the selected area electron diffraction 
(SAED) patterns display regularly arranged spots that indicate a kind of the single crystal structure. The (003), (101) and (107) lattice planes are ascribed to the rhombohedral $\mathrm{LiCoO}_{2}$-like structure, while (110) plane is assigned to the monoclinic $\mathrm{Li}_{2} \mathrm{MnO}_{3}$-like component. Actually, the as-prepared composites are the integration of rhombohedral structure and monoclinic structure of the layered transition metal oxides at the atomic level because of their similar cubic close-packed layers $[17,43]$. The result is consistent with the previous XRD analysis.

\subsection{Electrochemical performance}

The cycling performance (Fig. 6a) of the bare LMNCO and LMNCO/PSA was performed at a current density of $25 \mathrm{~mA} \mathrm{~g}^{-1}(0.1 \mathrm{C})$ between $2.0 \mathrm{~V}$ and $4.65 \mathrm{~V}$. The initial charge/discharge capacities of the LMNCO/PSA are $361.1 \mathrm{~mA} \mathrm{~h} \mathrm{~g} / 267.0 \mathrm{~mA} \mathrm{~h}$ $\mathrm{g}^{-1}$ with an initial coulombic efficiency of $73.9 \%$ that are superior to the bare LMNCO (335.0 $\left.\mathrm{mA} \mathrm{h} \mathrm{g}^{-1} / 234.2 \mathrm{~mA} \mathrm{~h} \mathrm{~g}^{-1}, 69.9 \%\right)$. Moreover, the discharge capacity of the LMNCO/PSA can still be maintained at $214.9 \mathrm{~mA} \mathrm{~h} \mathrm{~g}^{-1}$ after 100 cycles with high capacity retention of $80.5 \%$, while the bare LMNCO suffers from much lower discharge capacity of $187.8 \mathrm{~mA} \mathrm{~h} \mathrm{~g}^{-1}$ after 100 cycles with capacity retention of $80.2 \%$. Although both composites exhibit high coulombic efficiencies (>96\%) in the charge/discharge cycles, the LMNCO/PSA exhibits the improved specific capacity and good cyclability. Such excellent cycling performance is mainly attributed to the small particle size and porous structure that lead to the increment of specific surface area and the stabilization of the structure.

To better demonstrate and understand the effect of the introduced PSA in lithium 
storage, the rate capability of the bare LMNCO and LMNCO/PSA is also investigated from $0.1 \mathrm{C}$ to $10 \mathrm{C}$ between $2.0 \mathrm{~V}$ and $4.65 \mathrm{~V}$ as presented in Fig. 6b. Both samples reflect gradual reduction of the discharge specific capacity in the following high rate cycles. The capacity attenuation is believed to be mainly ascribed to the high polarization, which originates from the hindrance of $\mathrm{Li}^{+}$-extraction/insertion and lattice disorders at high rates. Obviously, the specific capacity of the LMNCO/PSA electrode holds an overwhelming advantage from $0.1 \mathrm{C}$ to $10 \mathrm{C}$ compared to the bare $\mathrm{LMNCO}$ electrode. The discharge capacity of the LMNCO/PSA sample is shown to be retained at 231.5, 203.5, 168.2, 144.4, 122.4, 95.5 and $64.3 \mathrm{~mA} \mathrm{~h} \mathrm{~g}^{-1}$ under $0.1 \mathrm{C}, 0.2 \mathrm{C}, 0.5 \mathrm{C}, 1 \mathrm{C}$, $2 \mathrm{C}, 5 \mathrm{C}$ and $10 \mathrm{C}$, respectively. When the current rate returns to $0.1 \mathrm{C}$ from $10 \mathrm{C}$, the discharge capacity of $220.0 \mathrm{~mA} \mathrm{~h} \mathrm{~g}^{-1}$ can still be achieved, indicating good capacity reversibility. As for the bare LMNCO, the discharge capacity descends faster especially at high rates $(5 \mathrm{C}, 10 \mathrm{C})$ that is down to nearly $1.0 \mathrm{~mA} \mathrm{~h} \mathrm{~g}^{-1}$ at $10 \mathrm{C}$. It can be concluded that the LMNCO/PSA is in possession of remarkable high-rate performance, which is significantly related to the enhanced electronic conductivity originated from the carbon residue and the unique porous structure for more $\mathrm{Li}^{+}$-diffusion paths.

Figs. $6 \mathrm{c}$ and d show the 1st, 2nd, 5th and 10th charge/discharge profiles of the bare LMNCO and LMNCO/PSA at $0.1 \mathrm{C}$ between 2.0 and $4.65 \mathrm{~V}$. Both samples present two platforms during the initial charge, located at 3.8-4.4 $\mathrm{V}$ and above $4.5 \mathrm{~V}$. The first one at 3.8-4.4 $\mathrm{V}$ corresponds to the de-lithiation of $\mathrm{LiMO}_{2}$ phase accompanied with the oxidation of $\mathrm{Ni}^{2+} \rightarrow \mathrm{Ni}^{4+}$ and $\mathrm{Co}^{3+} \rightarrow \mathrm{Co}^{4+}$. The second one located above $4.5 \mathrm{~V}$ is relevant with the extraction of $\mathrm{Li}_{2} \mathrm{O}$ from the layered $\mathrm{Li}_{2} \mathrm{MnO}_{3}$ lattice, leading to a large 
initial irreversible capacity loss [44]. Moreover, an increased platform at $2.5 \mathrm{~V}$ is newly formed in the initial discharging that is possibly because of the formation of spinel phases $[29,31,45]$. As clearly observed, the discharge capacity of the samples decreases gradually with cycling. One possible interpretation of the high irreversible capacity loss is that the contact of $\mathrm{Li}^{+}$and electrode-electrolyte interface is hindered by the SEI film. The bare LMNCO exhibits fairly stable discharge capacity at the first ten cycles as compared to the LMNCO/PSA, while the LMNCO/PSA delivers better specific capacities and higher coulombic efficiency. The discussion is well in agreement with the analysis of cycling performance.

Cyclic voltammetry (CV) measurements were conducted to study the redox reactions of transition metal ions. The CV curves of the bare LMNCO and LMNCO/PSA at a scan rate of $0.1 \mathrm{mV} \mathrm{s}^{-1}$ between $2.5 \mathrm{~V}$ and $4.65 \mathrm{~V}$ are shown in Figs. $7 \mathrm{a}$ and $\mathrm{b}$, respectively. Two main oxidation peaks can be observed in the initial charge, one at 4.12 $\mathrm{V}$ (or $4.06 \mathrm{~V}$ ) and the other at $4.63 \mathrm{~V}$, which is accordant with the above initial charge-discharge curves. The oxidation peak at $4.12 \mathrm{~V}$ (or $4.06 \mathrm{~V}$ ) is related to the $\mathrm{Li}^{+}$-extraction from $\mathrm{LiMO}_{2}$ with the oxidation of $\mathrm{Ni}^{2+}$ to $\mathrm{Ni}^{4+}$ and $\mathrm{Co}^{3+}$ to $\mathrm{Co}^{4+}$. The oxidation peak at $4.63 \mathrm{~V}$, which becomes weaker or even disappears in the following cycles, is corresponding to the electrochemical activation of $\mathrm{Li}_{2} \mathrm{MnO}_{3}$ accompanied with the extraction of $\mathrm{Li}_{2} \mathrm{O}$ from $\mathrm{Li}_{2} \mathrm{MnO}_{3}[46,47]$. In the discharge state, there are three reduction peaks located at $3.3 \mathrm{~V}, 3.8 \mathrm{~V}$ and $4.38 \mathrm{~V}$, respectively. The weak reduction peak at $3.3 \mathrm{~V}$ is associated with the reduction reaction of $\mathrm{Mn}^{4+}$ owing to the electrochemical activation reaction of $\mathrm{Li}_{2} \mathrm{MnO}_{3}$ in the initial charge process. The 
reduction peaks at $3.8 \mathrm{~V}$ and $4.4 \mathrm{~V}$ are attributed to the reduction of $\mathrm{Ni}^{4+}$ to $\mathrm{Ni}^{2+}$ and $\mathrm{Co}^{4+}$ to $\mathrm{Co}^{3+}$. It can be clearly seen that the reduction peaks at $3.8 \mathrm{~V}$ and $4.38 \mathrm{~V}$ are highly overlapped, indicating a good cyclic reversibility during the electrochemical reaction process. Moreover, redox peaks shift to lower potentials $[48,49]$, but the potential difference between oxidation peak and reduction peak of the LMNCO/PSA is smaller than that of the bare LMNCO, demonstrating a lower polarization effect. Furthermore, the peak intensity of the LMNCO/PSA is also obviously stronger compared with that of the bare LMNCO, which could be attributed to small particle size and less cation mixing during cycling.

Figs. $7 \mathrm{c}$ and $\mathrm{d}$ show the CV curves of the bare LMNCO and LMNCO/PSA at different scan rates $\left(0.1,0.2,0.4,0.8 \mathrm{mV} \mathrm{s}^{-1}\right)$ between $2.5 \mathrm{~V}$ and $4.65 \mathrm{~V}$. Apparently, with increasing the scan rate, oxidation peaks move to higher potentials while reduction peaks move to lower potentials. Figs. $7 \mathrm{e}$ and $\mathrm{f}$ exhibit the plots of peak current $\left(i_{\mathrm{p}}\right) v s$ the square root of scanning rates $\left(v^{1 / 2}\right)$ of the bare LMNCO and LMNCO/PSA. The low R-Squares represent high reliability of the fitting data. Here, the peak currents and scan rates follow the Randles-Sevcik equation [3].

$$
i_{\mathrm{p}}=\left(2.69 \times 10^{5}\right) n^{3 / 2} A D_{\mathrm{Li}+}{ }^{1 / 2} \mathrm{Cv}{ }^{1 / 2}
$$

where $i_{\mathrm{p}}$ is the peak current, $n$ is the electron transfer number of redox reactions $(n=1)$, $A$ is the effective surface area of the electrode $\left(2.54 \mathrm{~cm}^{2}\right), D_{\mathrm{Li}+}$ is the $\mathrm{Li}^{+}$diffusion coefficient, $C$ is the molar concentration of $\mathrm{Li}^{+}\left(0.099 \mathrm{~mol} \mathrm{~cm}{ }^{-3}\right)$ and $v$ is the scan rate. It can be calculated that $D_{\mathrm{Li}+}$ of oxidation peak and reduction peak for the bare LMCO are $6.83 \times 10^{-15} \mathrm{~cm}^{2} \mathrm{~s}^{-1}$ and $2.41 \times 10^{-15} \mathrm{~cm}^{2} \mathrm{~s}^{-1}$, respectively, while $D_{\mathrm{Li}+}$ of oxidation peak and 
reduction peak for the LMNCO/PSA are $1.49 \times 10^{-14}$ and $4.30 \times 10^{-15} \mathrm{~cm}^{2} \mathrm{~s}^{-1}$, respectively. This indicates the LMNCO/PSA exhibits faster kinetics of $\mathrm{Li}^{+}$compared with the bare LMNCO. The increase of $D_{\mathrm{Li}+}$ after adopting the PSA is due to the porous structure and enhanced electronic conductivity, which agrees well with the above analysis of rate capability.

Figs. 8a and b show the EIS spectra of the bare LMNCO and LMNCO/PSA at 1st, 5th and 10th cycle. The corresponding resistance fitting parameters are illustrated in Figs. $8 \mathrm{c}$ and $\mathrm{d}$, and the equivalent circuit for data fitting is shown in Fig. 8e. As illustrated, a semicircle in high-frequency and a large arc in intermediate-frequency regions can be observed, which present the SEI resistance $\left(R_{\mathrm{f}}\right)$ and the charge transfer resistance at the electrode/electrolyte interface $\left(R_{\mathrm{ct}}\right)$, respectively [50]. Besides, in this model, $R_{\mathrm{e}}$ is the internal resistance, $Z_{\mathrm{w}}$ is the Warburg impedance of the $\mathrm{Li}^{+}$solid-state diffusion in the bulk crystal [51], $C P E_{\mathrm{f}}$ and $C P E_{\mathrm{ct}}$ are the nonideal capacitance of the SEI layer and the double layer, respectively [52]. Both samples have no distinct variation in $R_{\mathrm{e}}$, but the internal resistance of the LMNCO/PSA is slightly smaller than the bare LMNCO. Due to the growth of SEI film and electrolyte decomposition at high voltage, $R_{\mathrm{f}}$ of the bare LMNCO increases gradually upon cycling. Initially, $R_{\mathrm{f}}$ of the LMNCO/PSA rises significantly and then remains almost unchanged in the subsequent cycles. The bare LMNCO exhibits an evident increment in $R_{\mathrm{ct}}$ from $2114 \Omega$ to $2969 \Omega$ after 10 cycles, revealing the interior structural instability or transformation, whereas $R_{\mathrm{ct}}$ of the LMNCO/PSA keeps a stable level at around $1880 \Omega$. In short, the LMNCO/PSA electrode exhibits lower initial SEI resistance $(68.65 \Omega)$, charge transfer resistance 
(about $1880 \Omega$ ) and total impedance, indicating the effect of the PSA decomposition product on the effective stabilization of the structure and electrode/electrolyte interface, thus further leading to better cyclability and rate capability.

\section{Conclusions}

In summary, the layered oxide $\mathrm{Li}_{1.165} \mathrm{Mn}_{0.501} \mathrm{Ni}_{0.167} \mathrm{Co}_{0.167} \mathrm{O}_{2}$ with high performance and porous structure has been successfully prepared by adopting PSA (polymer microsphere) as a template and conductive agent via a co-precipitation route combined with high-temperature calcination. The precursor presents a spherical shape by embedding the PSA in the transition metal carbonate matrix. After calcined at high temperature, the material maintains the spherical morphology with small particle size and porous structure despite of suffering from the drastic loss of carbon. The electrochemical measurements demonstrate that the PSA-assisted material exhibits excellent cycling performance and high rate capability. It can deliver a high initial discharge capacity of $267.0 \mathrm{~mA} \mathrm{~h} \mathrm{~g}^{-1}$ and maintain a stable discharge capacity of 214.9 $\mathrm{mA} \mathrm{h} \mathrm{g}{ }^{-1}$ after 100 cycles at $0.1 \mathrm{C}\left(1 \mathrm{C}=250 \mathrm{~mA} \mathrm{~g}^{-1}\right)$ between 2.0 and $4.65 \mathrm{~V}$. Its initial coulombic efficiency has been elevated from $69.9 \%$ to $73.9 \%$. Meanwhile, the discharge capacity of $64.3 \mathrm{~mA} \mathrm{~h} \mathrm{~g}^{-1}$ can also be attained under $10 \mathrm{C}$ current density. The excellent performance is attributed to small particle size, porous structure and carbon residue that are extremely advantageous to shorten the $\mathrm{Li}^{+}$diffusion distance and enhance the electronic conductivity, leading to the improved cycling stability and rate capability. Therefore, this novel strategy is believed to be promising to enhance the 
electrochemical performance and further expand to the commercial applications of high-power lithium-ion batteries.

\section{Acknowledgements}

This work was financially supported by the National Science Foundation of China (NSFC, Nos. 51201066 and 51171065), the Natural Science Foundation of Guangdong Province (No. S2012020010937), the Scientific and Technological Plan of Guangdong Province (No. 2013B010403032), the education department of Guangdong province science and technology innovation project (No. 2013KJCX0183) and the Hong Kong Polytechnic University (4-ZZDC) and Strategic Plan (1-ZVCG).

\section{References}

[1] L.X. Zhang, Y.L. Wang, H.F. Jiu, H.Y. Qiu, H.Y. Wang, Hollow core-shell $\mathrm{ZnMn}_{2} \mathrm{O}_{4}$ microspheres as a high-performance anode material for lithium-ion batteries, Ceram. Int. 41 (2015) 9655-9661.

[2] H.J. Noh, S. Youn, C.S. Yoon, Y.K. Sun, Comparison of the structural and electrochemical properties of layered $\mathrm{Li}\left[\mathrm{Ni}_{\mathrm{x}} \mathrm{Co}_{\mathrm{y}} \mathrm{Mn}_{\mathrm{z}}\right] \mathrm{O}_{2}(\mathrm{x}=1 / 3,0.5,0.6,0.7,0.8$ and 0.85$)$ cathode material for lithium-ion batteries, J. Power Sources 233 (2013) 121-130.

[3] Y.L. Huang, X.H. Hou, S.M. Ma, X.L. Zou, Y.P. Wu, S.J. Hu, Z.P. Shao, X. Liu, Template GNL-assisted synthesis of porous $\mathrm{Li}_{1.2} \mathrm{Mn}_{0.534} \mathrm{Ni}_{0.133} \mathrm{Co}_{0.133} \mathrm{O}_{2}$ : towards high performance cathodes for lithium ion batteries, RSC Adv. 5 (2015) 25258-25265.

[4] X. Jiang, Z.H. Wang, D. Rooney, X.X. Zhang, J. Feng, J.S. Qiao, W. Sun, K.N. Sun, A design strategy of large grain lithium-rich layered oxides for lithium-ion batteries cathode, Electrochim. Acta 160 
(2015) 131-138.

[5] X.H. Hou, X.L. Zou, Y.L. Huang, S.J. Hu, Q. Ru, Y.M. Gao, Surfactant CTAB-assisted synthesis of $\mathrm{Li}_{1.13}\left[\mathrm{Ni}_{0.233} \mathrm{Mn}_{0.534} \mathrm{Co}_{0.233}\right]_{0.87} \mathrm{O}_{2}$ with festoon-like hierarchical architectures as cathode materials for Li-ion batteries with outstanding performance, RSC Adv. 4 (2014) 29534-29541.

[6] P. Manikandan, P. Periasamy, R. Jagannathan, Microstructure-twinning and hexad multiplet(s) in lithium-rich layered cathode materials for lithium-ion batteries, RSC Adv. 4 (2014) 40359-40367.

[7] X.W. Miao, Y. Yan, C.G. Wang, L.L. Cui, J.H. Fang, G. Yang, Optimal microwave-assisted hydrothermal synthesis of nanosized $\mathrm{xLi}_{2} \mathrm{MnO}_{3} \cdot(1-\mathrm{x}) \mathrm{LiNi}_{1 / 3} \mathrm{Co}_{1 / 3} \mathrm{Mn}_{1 / 3} \mathrm{O}_{2}$ cathode materials for lithium ion battery, J. Power Sources 247 (2014) 219-227.

[8] W.W. Zhao, S. Yamamoto, A. Tanaka, H. Noguchi, Synthesis of Li-excess layered cathode material with enhanced reversible capacity for Lithium ion batteries through the optimization of precursor synthesis method, Electrochim. Acta 143 (2014) 347-356.

[9] F. Fu, Y.Y. Huang, P. Wu, Y.K. Bu, Y.B. Wang, J.N. Yao, Controlled synthesis of lithium-rich layered $\mathrm{Li}_{1.2} \mathrm{Mn}_{0.56} \mathrm{Ni}_{0.12} \mathrm{Co}_{0.12} \mathrm{O}_{2}$ oxide with tunable morphology and structure as cathode material for lithium-ion batteries by solvo/hydrothermal methods, J. Alloys Compd. 618 (2015) 673-678.

[10] Q.R. Xue, J.L. Li, G.F. Xu, H.W. Zhou, X.D. Wang, F.Y. Kang, In situ polyaniline modified cathode material $\mathrm{Li}\left[\mathrm{Li}_{0.2} \mathrm{Mn}_{0.54} \mathrm{Ni}_{0.13} \mathrm{Co}_{0.13}\right] \mathrm{O}_{2}$ with high rate capacity for lithium ion batteries, J. Mater. Chem. A 2 (2014) 18613-18623.

[11] H.J. Yu, H.S. Zhou, High-Energy Cathode Materials $\left(\mathrm{Li}_{2} \mathrm{MnO}_{3}-\mathrm{LiMO}_{2}\right)$ for Lithium-Ion Batteries, J. Phys. Chem. Lett. 4 (2013) 1268-1280.

[12] M.H. Shao, In situ microscopic studies on the structural and chemical behaviors of lithium-ion battery materials, J. Power Sources 270 (2014) 475-486. 
[13] B. Ebin, G. Lindbergh, S. Gürmen, Preparation and electrochemical properties of nanocrystalline $\mathrm{LiB}_{\mathrm{x}} \mathrm{Mn}_{2-\mathrm{x}} \mathrm{O}_{4}$ cathode particles for Li-ion batteries by ultrasonic spray pyrolysis method, J. Alloys Compd. 620 (2015) 399-406.

[14] D. Mohanty, S. Kalnaus, R.A. Meisner, A.S. Safat, J.L. Li, E.A. Payzant, K. Rhodes, D.L. Wood, C. Daniel, Structural transformation in a $\mathrm{Li}_{1.2} \mathrm{Co}_{0.1} \mathrm{Mn}_{0.55} \mathrm{Ni}_{0.15} \mathrm{O}_{2}$ lithium-ion battery cathode during high-voltage hold, RSC Adv. 3 (2013) 7479-7485.

[15] M. Gu, I. Belharouak, J.M. Zheng, H.M. Wu, J. Xiao, A. Genc, K. Amine, S. Thevuthasan, D.R. Baer, J.G. Zhang, N.D. Browning, J. Liu, C.M. Wang, Formation of the Spinel Phase in the Layered Composite Cathode Used in Li-Ion Batteries, ACS Nano 7 (2013) 760-767.

[16] Y.H. Deng, S.Q. Liu, X.X. Liang, Study of carbon surface-modified $\mathrm{Li}\left[\mathrm{Li}_{0.2} \mathrm{Mn}_{0.54} \mathrm{Ni}_{0.13} \mathrm{Co}_{0.13}\right] \mathrm{O}_{2}$ for high-capacity lithium ion battery cathode, J. Solid State Electrochem. 17 (2013) 1067-1075.

[17] J. Zhang, Q.W. Lu, J.H. Fang, J.L. Wang, J. Yang, Y.N. NuLi, Polyimide Encapsulated Lithium-Rich Cathode Material for High Voltage Lithium-Ion Battery, ACS Appl. Mater. Interfaces 6 (2014) 17965-17973.

[18] J. Li, R. Klöpsch, M.C. Stan, S. Nowak, M. Kunze, M. Winter, S. Passerini, Synthesis and electrochemical performance of the high voltage cathode material $\mathrm{Li}\left[\mathrm{Li}_{0.2} \mathrm{Mn}_{0.56} \mathrm{Ni}_{0.16} \mathrm{Co}_{0.08}\right] \mathrm{O}_{2}$ with improved rate capability, J. Power Sources 196 (2011) 4821-4825.

[19] X.K. Yang, X.Y. Wang, G.S. Zou, L. Hu, H.B. Shu, S.Y. Yang, L. Liu, H. Hu, H. Yuan, B.N. Hu, Q.L. Wei, L.H. Yi, Spherical lithium-rich layered $\mathrm{Li}_{1.13}\left[\mathrm{Mn}_{0.534} \mathrm{Ni}_{0.233} \mathrm{Co}_{0.233}\right]_{0.87} \mathrm{O}_{2}$ with concentration-gradient outer layer as high-performance cathodes for lithium ion batteries, J. Power Sources 232 (2013) 338-347.

[20] Q.G. Zhang, T.Y. Peng, D. Zhan, X.H. Hu, Synthesis and electrochemical property of 
$\mathrm{xLi}_{2} \mathrm{MnO}_{3} \cdot(1-\mathrm{x}) \mathrm{LiMnO}_{2}$ composite cathode materials derived from partially reduced $\mathrm{Li}_{2} \mathrm{MnO}_{3}, \mathrm{~J}$. Power Sources 250 (2014) 40-49.

[21] D. Mohanty, A.S. Sefat, S. Kalnaus, J.L. Li, R.A. Meisner, E.A. Payzant, D.P. Abraham, D.L. Wood, C. Daniel, Investigating phase transformation in the $\mathrm{Li}_{1.2} \mathrm{Co}_{0.1} \mathrm{Mn}_{0.55} \mathrm{Ni}_{0.15} \mathrm{O}_{2}$ lithium-ion battery cathode during high-voltage hold $(4.5 \mathrm{~V})$ via magnetic, X-ray diffraction and electron microscopy studies, J. Mater. Chem. A 1 (2013) 6249-6261.

[22] J.L. Liu, M.Y. Hou, J. Yi, S.S. Guo, C.X. Wang, Y.Y. Xia, Improving the electrochemical performance of Layered lithium-rich transition-metal oxides by controlling the structural defects, Energy Environ. Sci. 7 (2014) 705-714.

[23] X.H. Zhang, D. Luo, G.S. Li, J. Zheng, C. Yu, X.F. Guan, C.C. Fu, X.D. Huang, L.P. Li, Self-adjusted oxygen-partial-pressure approach to the improved electrochemical performance of electrode $\mathrm{Li}\left[\mathrm{Li}_{0.14} \mathrm{Mn}_{0.47} \mathrm{Ni}_{0.25} \mathrm{Co}_{0.14}\right] \mathrm{O}_{2}$ for lithium-ion batteries, J. Mater. Chem. A 1 (2013) 9721-9729.

[24] J. Wang, B. Qiu, H.L. Cao, Y.G. Xia, Z.P. Liu, Electrochemical properties of $0.6 \mathrm{Li}\left[\mathrm{Li}_{1 / 3} \mathrm{Mn}_{2 / 3}\right] \mathrm{O}_{2} \cdot 0.4 \mathrm{LiNi}_{\mathrm{x}} \mathrm{Mn}_{\mathrm{y}} \mathrm{Co}_{1-\mathrm{x}-\mathrm{y}} \mathrm{O}_{2}$ cathode materials for lithium-ion batteries, J. Power Sources 218 (2012) 128-133.

[25] J. Liu, A. Manthiram, Functional surface modifications of a high capacity layered $\mathrm{Li}\left[\mathrm{Li}_{0.2} \mathrm{Mn}_{0.54} \mathrm{Ni}_{0.13} \mathrm{Co}_{0.13}\right] \mathrm{O}_{2}$ cathode, J. Mater. Chem. 20 (2010) 3961-3967.

[26] H.Q. Li, H.S. Zhou, Enhancing the performances of Li-ion batteries by carbon-coating: present and future, Chem. Commun. 48 (2012) 1201-1217.

[27] B.H. Song, C.F. Zhou, Y. Chen, Z.W. Liu, M.O. Lai, J.M. Xue, L. Lu, Role of carbon coating in improving electrochemical performance of Li-rich $\mathrm{Li}\left(\mathrm{Li}_{0.2} \mathrm{Mn}_{0.54} \mathrm{Ni}_{0.13} \mathrm{Co}_{0.13}\right) \mathrm{O}_{2}$ cathode, RSC Adv. 4 
(2014) 44244-44252.

[28] Y.L. Yao, H.C. Liu, G.C. Li, H.R. Peng, K.Z. Chen, Synthesis and electrochemical performance of phosphate-coated porous $\mathrm{LiNi}_{1 / 3} \mathrm{Co}_{1 / 3} \mathrm{Mn}_{1 / 3} \mathrm{O}_{2}$ cathode material for lithium ion batteries, Electrochim. Acta 113 (2013) 340-345.

[29] H. Liu, C.Y. Du, G.P. Yin, B. Song, P.J. Zuo, X.Q. Cheng, Y.L. Ma, Y.Z. Gao, An Li-rich oxide cathode material with mosaic spinel grain and a surface coating for high performance Li-ion batteries, J. Mater. Chem. A 2 (2014) 15640-15646.

[30] H.Z. Zhang, Q.Q. Qiao, G.R. Li, X.P. Gao, $\mathrm{PO}_{4}{ }^{3-}$ polyanion-doping for stabilizing Li-rich layered oxides as cathode materials for advanced lithium-ion batteries, J. Mater. Chem. A 2 (2014) $7454-7460$

[31] B.H. Song, M.O. Lai, Z.W. Liu, H.W. Liu, L. Lu, Graphene-based surface modification on layered Li-rich cathode for high-performance Li-ion batteries, J. Mater. Chem. A 1 (2013) 9954-9965.

[32] Q. Li, G.S. Li, C.C. Fu, D. Luo, J.M. Fan, L.P. Li, K ${ }^{+}$-Doped $\mathrm{Li}_{1.2} \mathrm{Mn}_{0.54} \mathrm{Co}_{0.13} \mathrm{Ni}_{0.13} \mathrm{O}_{2}$ : A Novel Cathode Material with an Enhanced Cycling Stability for Lithium-Ion Batteries, ACS Appl. Mater. Interfaces 6 (2014) 10330-10341.

[33] Z.Y. Wang, B. Li, J. Ma, D.G. Xia, Molten salt synthesis and high-performance of nanocrystalline Li-rich cathode materials, RSC Adv. 4 (2014) 15825-15829.

[34] S.J. Shi, J.P. Tu, Y.Y. Tang, Y.Q. Zhang, X.L. Wang, C.D. Gu, Preparation and characterization of macroporous $\mathrm{Li}_{1.2} \mathrm{Mn}_{0.54} \mathrm{Ni}_{0.13} \mathrm{Co}_{0.13} \mathrm{O}_{2}$ cathode material for lithium-ion batteries via aerogel template, J. Power Sources 240 (2013) 140-148.

[35] M. Gao, F. Lian, H.Q. Liu, C.J. Tian, L.L. Ma, W.Y. Yang, Synthesis and electrochemical performance of long lifespan Li-rich $\mathrm{Li}_{1+\mathrm{x}}\left(\mathrm{Ni}_{0.37} \mathrm{Mn}_{0.63}\right)_{1-\mathrm{x}} \mathrm{O}_{2}$ cathode materials for lithium-ion 
batteries, Electrochim. Acta 95 (2013) 87-94.

[36] J.Q. Zhao, S. Aziz, Y. Wang, Hierarchical functional layers on high-capacity lithium-excess cathodes for superior lithium ion batteries, J. Power Sources 247 (2014) 95-104.

[37] S.H. Guo, H.J. Yu, P. Liu, X.Z. Liu, D. Li, M.W. Chen, M. Ishida, H.S. Zhou, Surface coating of lithium-manganese-rich layered oxides with delaminated $\mathrm{MnO}_{2}$ nanosheets as cathode materials for Li-ion batteries, J. Mater. Chem. A 2 (2014) 4422-4428.

[38] J.G. Yang, F.Y. Cheng, X.L. Zhang, H.Y. Gao, Z.L. Tao, J. Chen, Porous $0.2 \mathrm{Li}_{2} \mathrm{MnO}_{3} \cdot 0.8 \mathrm{LiNi}_{0.5} \mathrm{Mn}_{0.5} \mathrm{O}_{2}$ nanorods as cathode materials for lithium-ion batteries, J. Mater. Chem. A 2 (2014) 1636-1640.

[39] O. Akhavan, Graphene Nanomesh by ZnO Nanorod Photocatalysts, ACS Nano 4 (2010) 4174-4180.

[40] J.W. Mao, X.H. Hou, X.Y. Wang, G.N. He, Z.P. Shao, S.J. Hu, Corncob-shaped $\mathrm{ZnFe}_{2} \mathrm{O}_{4} / \mathrm{C}$ nanostructures for improved anode rate and cycle performance in lithium-ion batteries, RSC Adv. 5 (2015) 31807-31814.

[41] W.X. Zhang, Y.Z. Wang, Characterizing on the Structure of High Molecular Weight PAN Synthesized in DMSO/H $\mathrm{H}_{2} \mathrm{O}$, J. Zhongyuan Inst. Tech. 15 (2004) 19-23.

[42] Q.S. Xie, F. Li, H.Z. Guo, L.S. Wang, Y.Z. Chen, G.H. Yue, D.L. Peng, Template-Free Synthesis of Amorphous Double-Shelled Zinc-Cobalt Citrate Hollow Microspheres and Their Transformation to Crystalline $\mathrm{ZnCo}_{2} \mathrm{O}^{4}$ Microspheres, ACS Appl. Mater. Interfaces 5 (2013) 5508-5517.

[43] X.H. Hou, Y.L. Huang, S.M. Ma, X.L. Zou, S.J. Hu, Y.P. Wu, Facile hydrothermal method synthesis of coralline-like $\mathrm{Li}_{1.2} \mathrm{Mn}_{0.54} \mathrm{Ni}_{0.13} \mathrm{Co}_{0.13} \mathrm{O}_{2}$ hierarchical architectures as superior cathode materials for lithium-ion batteries, Mater. Res. Bull. 63 (2015) 256-264.

[44] G.B. Liu, H. Liu, Y.F. Shi, The synthesis and electrochemical properties of $\mathrm{xLi}_{2} \mathrm{MnO}_{3} \cdot(1-\mathrm{x}) \mathrm{MO}_{2}(\mathrm{M}$ 
$\left.=\mathrm{Mn}_{1 / 3} \mathrm{Ni}_{1 / 3} \mathrm{Fe}_{1 / 3}\right)$ via co-precipitation method, Electrochim. Acta 88 (2013) 112-116.

[45] B.H. Song, H.W. Liu, Z.W. Liu, P.F. Xiao, M.O. Lai, L. Lu, High rate capability caused by surface cubic spinels in Li-rich layer-structured cathodes for Li-ion batteries, Sci. Rep. 3 (2013) 3094-3106.

[46] S.J. Shi, J.P. Tu, Y.Y. Tang, Y.X. Yu, Y.Q. Zhang, X.L. Wang, Synthesis and electrochemical performance of $\mathrm{Li}_{1.131} \mathrm{Mn}_{0.504} \mathrm{Ni}_{0.243} \mathrm{Co}_{0.122} \mathrm{O}_{2}$ cathode materials for lithium ion batteries via freeze drying, J. Power Sources 221 (2013) 300-307.

[47] J.Q. Zhao, Y. Wang, High-capacity full lithium-ion cells based on nanoarchitectured ternary manganese-nickel-cobalt carbonate and its lithiated derivative, J. Mater. Chem. A 2 (2014) $14947-14956$.

[48] X. Wei, S.C. Zhang, Z.J. Du, P.H. Yang, J. Wang, Y.B. Ren, Electrochemical performance of high-capacity nanostructured $\mathrm{Li}\left[\mathrm{Li}_{0.2} \mathrm{Mn}_{0.54} \mathrm{Ni}_{0.13} \mathrm{Co}_{0.13}\right] \mathrm{O}_{2}$ cathode material for lithium ion battery by hydrothermal method, Electrochim. Acta 107 (2013) 549-554.

[49] H.F. Li, J. Pang, Y.P. Yin, W.D. Zhuang, H. Wang, C.X. Zhai, S.G. Lu, Application of a nonflammable electrolyte containing PP13TFSI ionic liquid for lithium-ion batteries using the high capacity cathode material $\mathrm{Li}\left[\mathrm{Li}_{0.2} \mathrm{Mn}_{0.54} \mathrm{Ni}_{0.13} \mathrm{Co}_{0.13}\right] \mathrm{O}_{2}$, RSC Adv. 3 (2013) 13907-13914.

[50] B. Li, Y.Y. Yu, J.B. Zhao, Facile synthesis of spherical $\mathrm{xLi}_{2} \mathrm{MnO}_{3} \cdot(1-\mathrm{x}) \mathrm{Li}\left(\mathrm{Mn}_{0.33} \mathrm{Co}_{0.33} \mathrm{Ni}_{0.33}\right) \mathrm{O}_{2}$ as cathode materials for lithium-ion batteries with improved electrochemical performance, J. Power Sources 275 (2015) 64-72.

[51] G.Q. Tan, F. Wu, J. Lu, R.J. Chen, L. Li, K. Amine, Controllable crystalline preferred orientation in Li-Co-Ni-Mn oxide cathode thin films for all-solid-state lithium batteries, Nanoscale 6 (2014) 10611-10622.

[52] X.D. Xiang, W.S. Li, Self-directed chemical synthesis of lithium-rich layered oxide 
$\mathrm{Li}\left[\mathrm{Li}_{0.2} \mathrm{Ni}_{0.2} \mathrm{Mn}_{0.6}\right] \mathrm{O}_{2}$ with tightly interconnected particles as cathode of lithium ion batteries with improved rate capability, Electrochim. Acta 127 (2014) 259-265.

\section{Figure captions}

Scheme 1. Schematic illustration of the synthesis mechanism of the LMNCO/PSA composite.

Fig. 1. TG curve of the PSA.

Fig. 2. (a) XRD patterns of the precursors of the bare LMNCO and LMNCO/PSA; (b) XRD patterns of the bare LMNCO and LMNCO/PSA materials after high temperature calcination.

Fig. 3. (a) Raman spectra and (b) FT-IR spectra of the bare LMNCO and LMNCO/PSA composites.

Fig. 4. SEM images of the precursors and composites of (a,c) bare LMNCO and (b,d) LMNCO/PSA; SEM images of (e) PSA and (f) the cross-section of the LMNCO/PSA.

Fig. 5. TEM images of (a) the bare LMNCO and (b) LMNCO/PSA; the corresponding SAED patterns of (c) the bare LMNCO and (d) LMNCO/PSA.

Fig. 6. Electrochemical performances of the bare LMNCO and LMNCO/PSA electrodes between $2.0 \mathrm{~V}$ and $4.65 \mathrm{~V}$ : (a) cycling performance at $0.1 \mathrm{C}$; (b) rate capability at different rates; the 1st, 2nd, 5th and 10th charge/discharge profiles at $0.1 \mathrm{C}$ of (c) the bare LMNCO electrode and (d) the LMNCO/PSA electrode.

Fig. 7. Cyclic voltammograms at the scan rate of $0.1 \mathrm{mV} \mathrm{s}^{-1}$ of (a) the bare LMNCO and (b) LMNCO/PSA; Cyclic voltammograms at different scan rates of 0.1, 0.2, 0.4 and 0.8 
$\mathrm{mV} \mathrm{s}^{-1}$ of (c) the bare LMNCO and (d) LMNCO/PSA; the plots of peak currents $\left(i_{\mathrm{p}}\right) v s$ the square root of scan rates $\left(v^{1 / 2}\right)$ of (e) the bare LMNCO and (f) LMNCO/PSA.

Fig. 8. EIS spectra and corresponding fitting parameters of $(a, c)$ the bare LMNCO and (b,d) LMNCO/PSA after 1, 5 and 10 cycles; (e) the equivalent circuit for data fitting. 


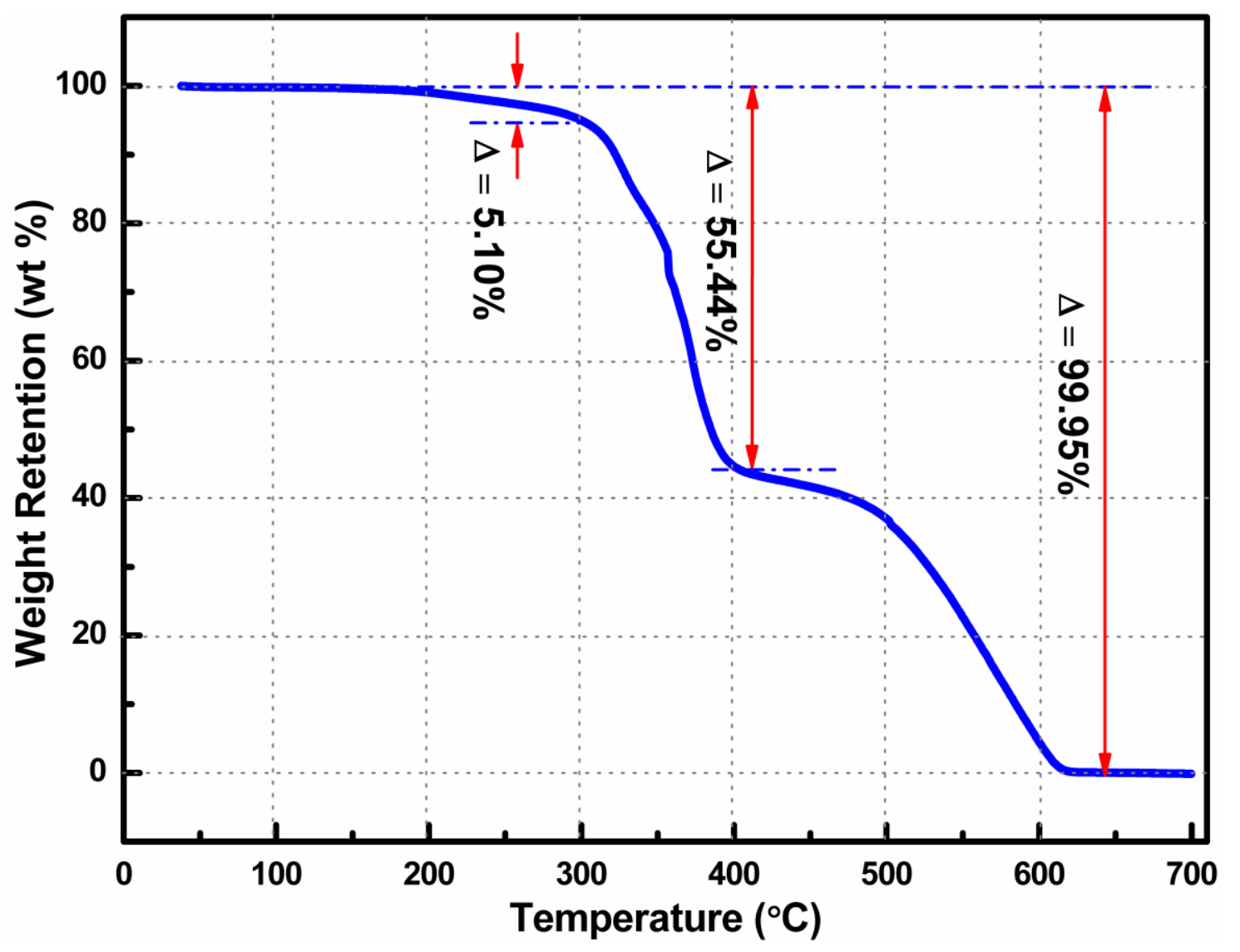




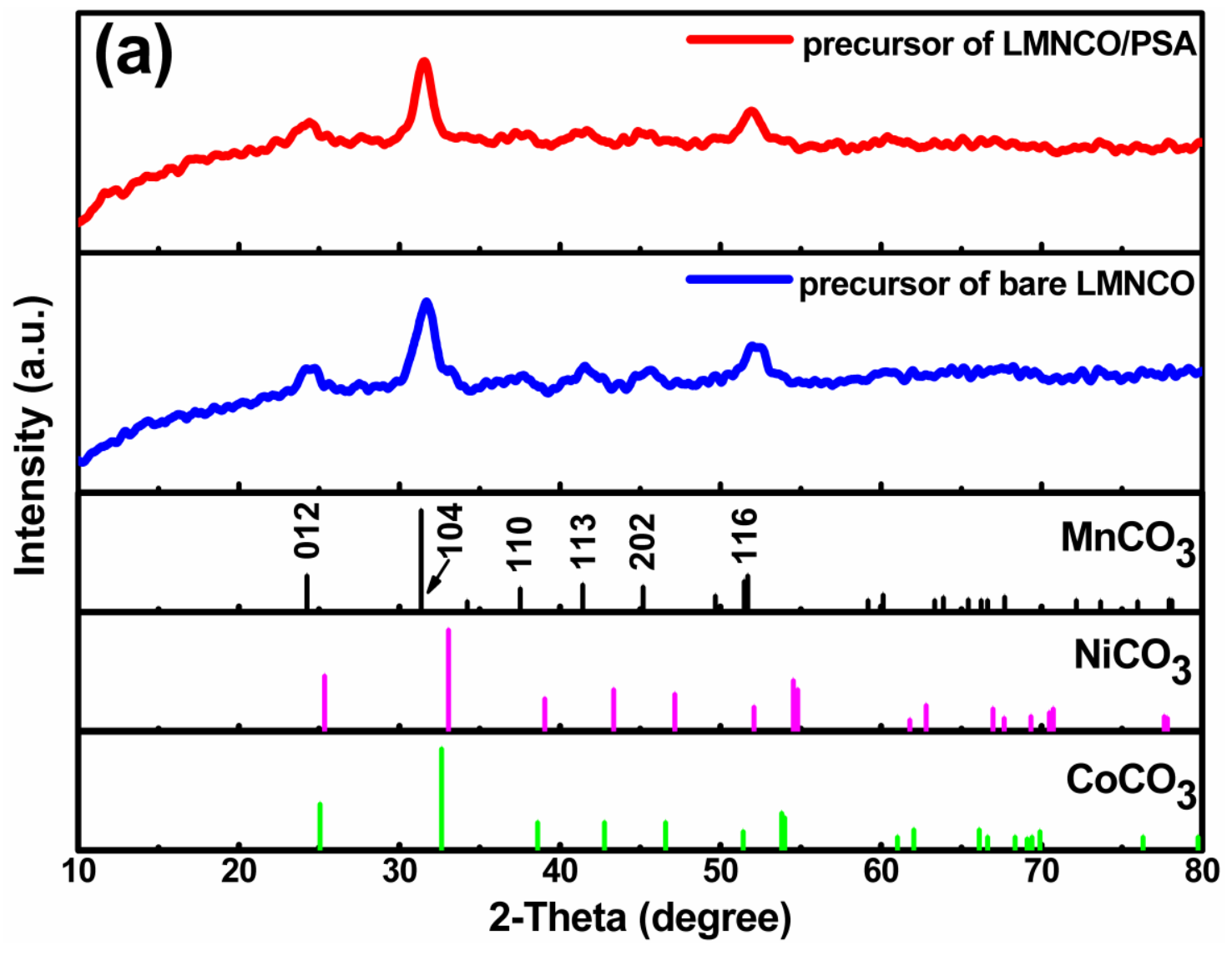




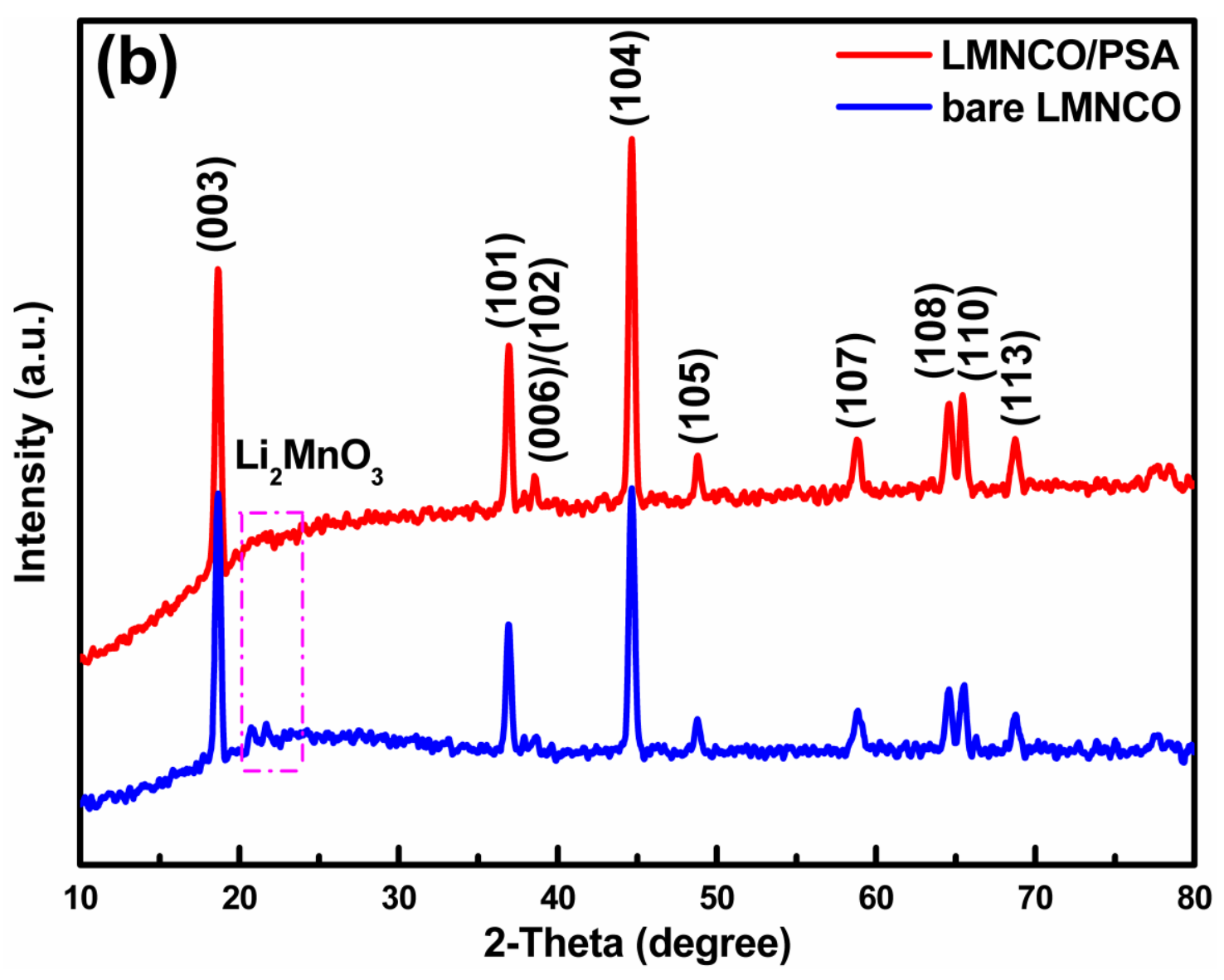




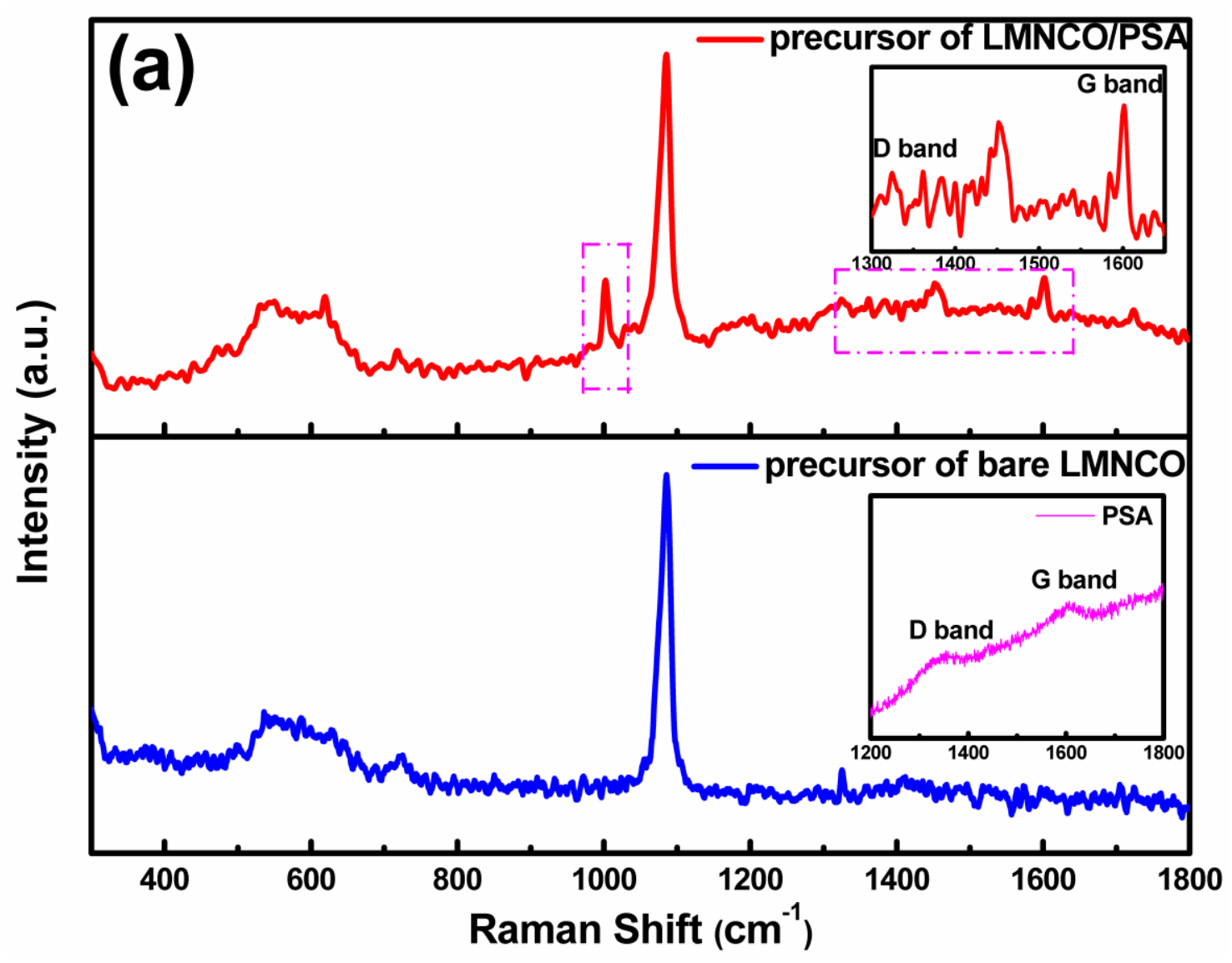




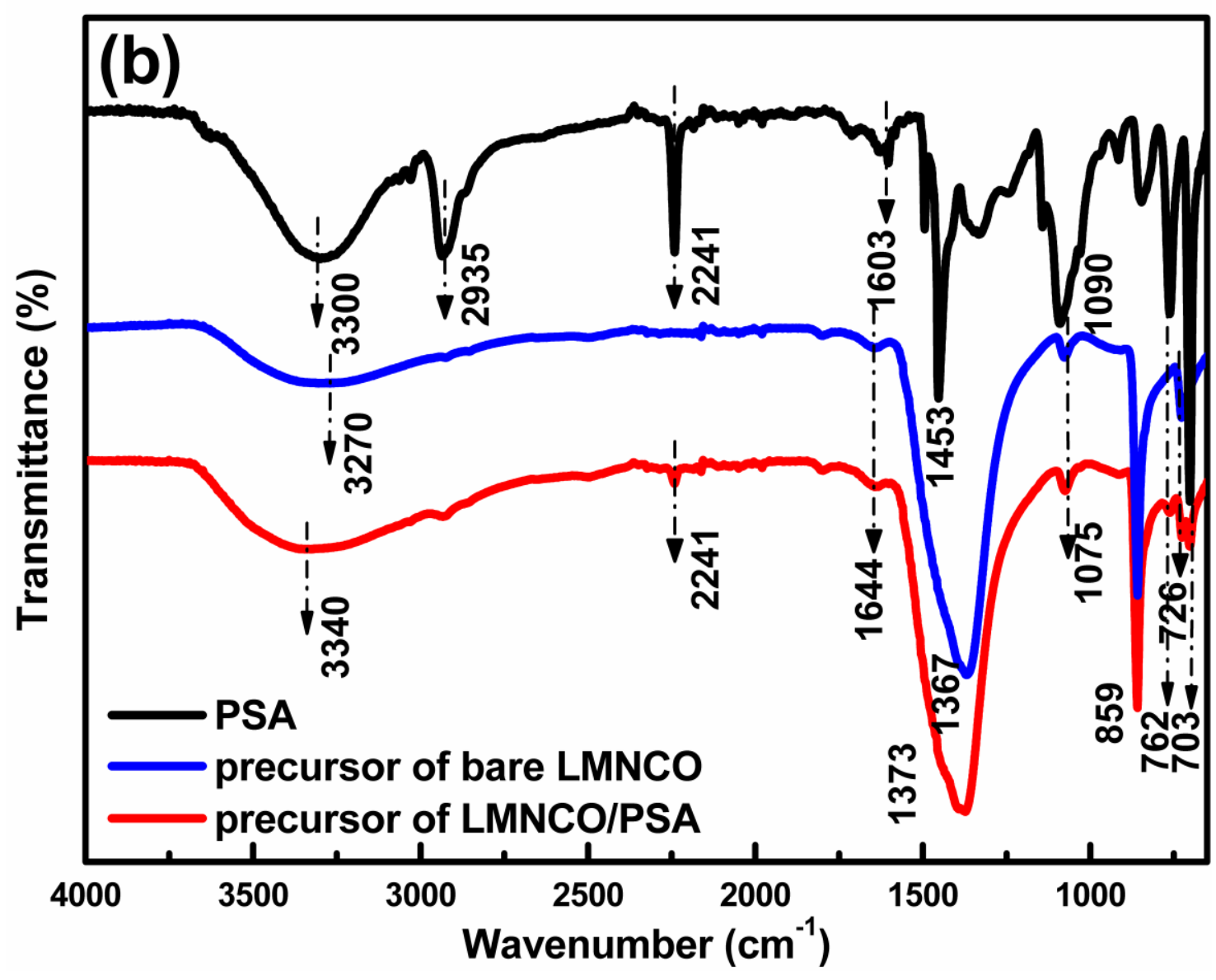




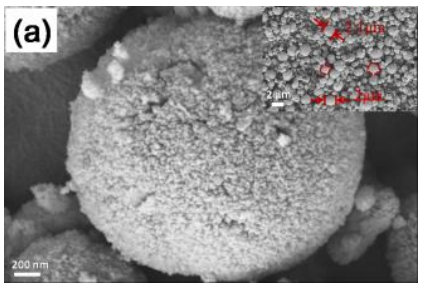




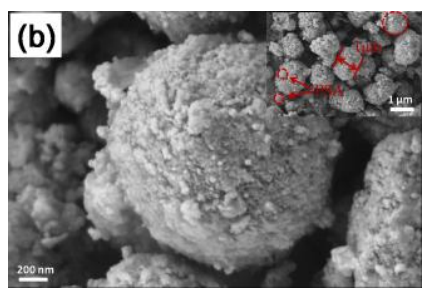




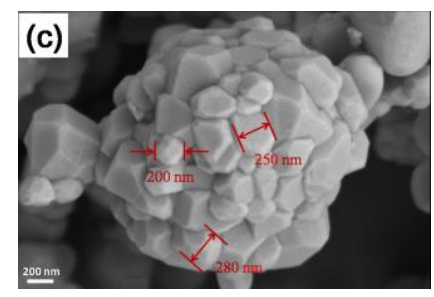




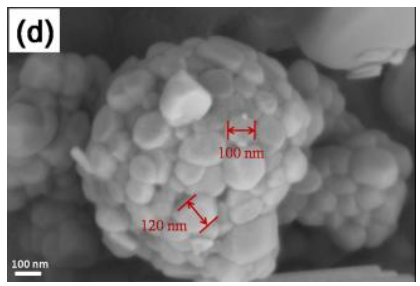




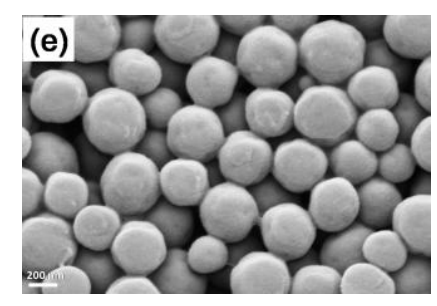




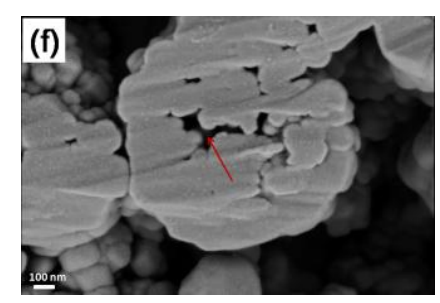


(a)

R (001) $C 2 / m$ and/or (003) $R-3 m$

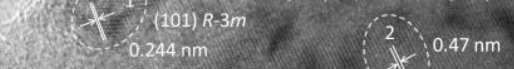

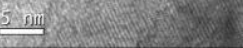


(b)

(001) $C 2 / m$ and/or (003) R-3m

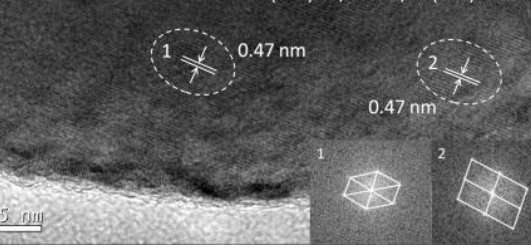


(c)

$\stackrel{(101) \rightarrow(003)}{\rightarrow}$

(107)

$5.1 / \mathrm{nm}$ 
(d)

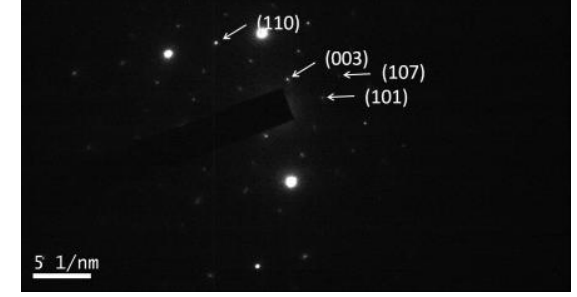




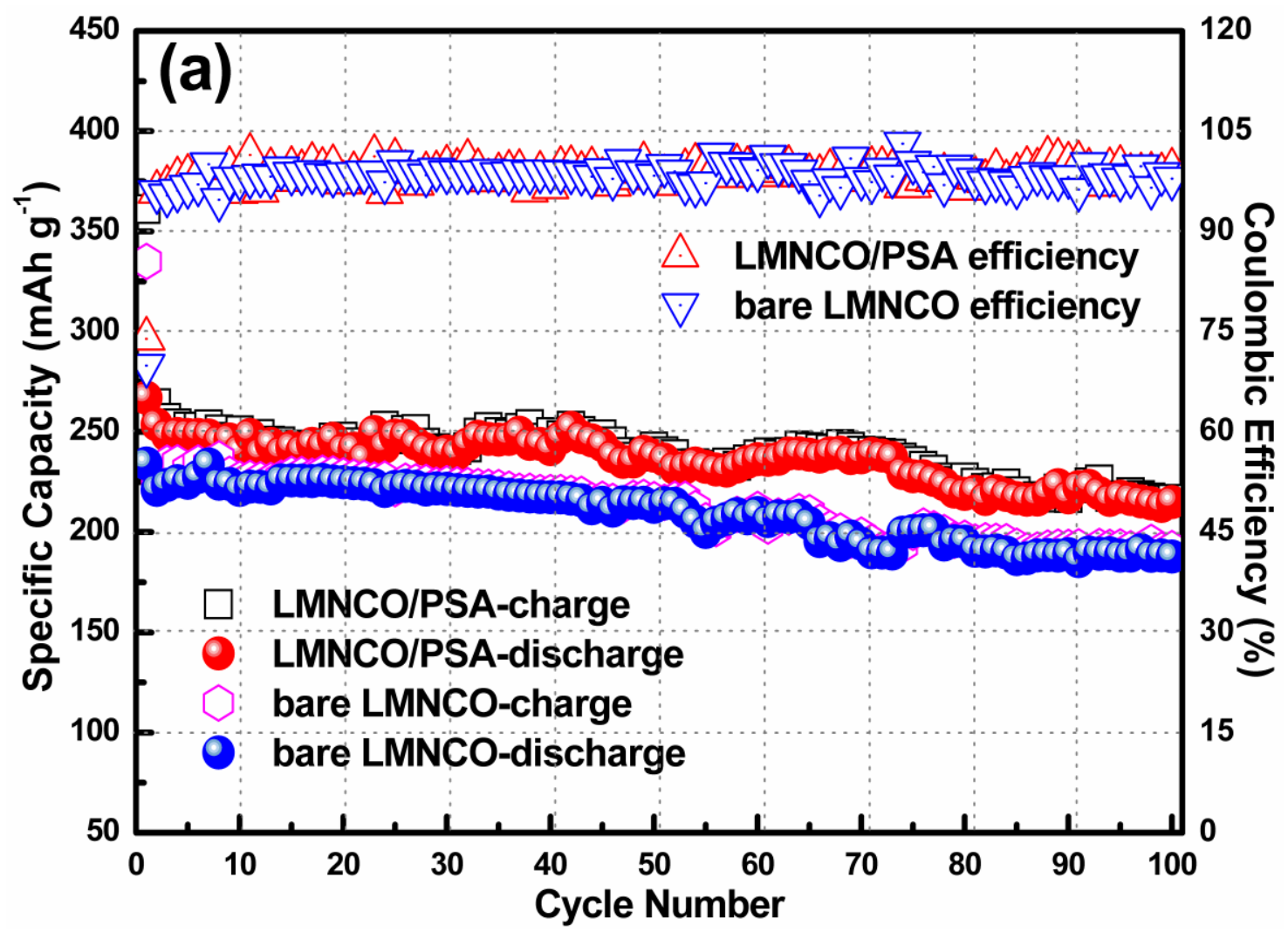




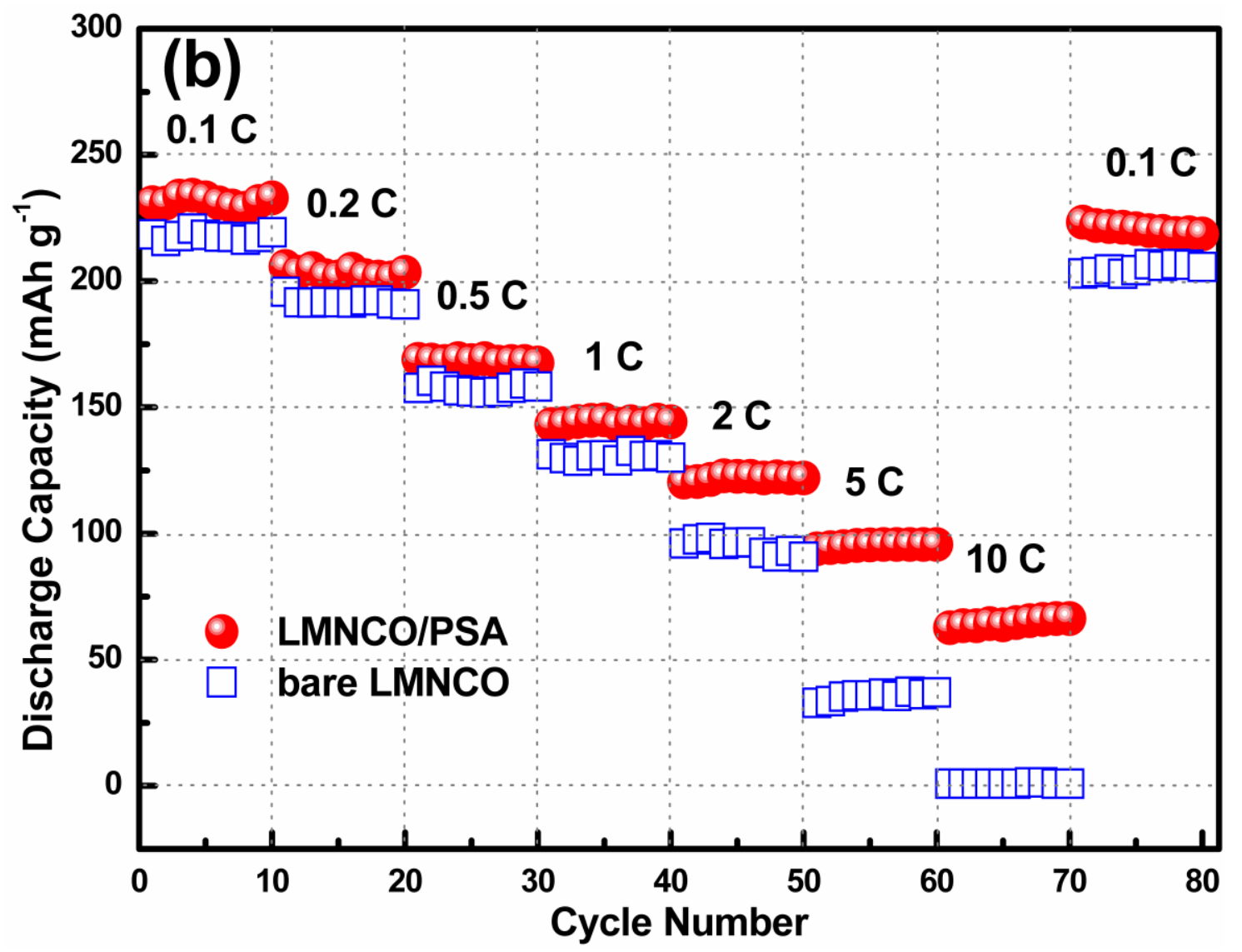




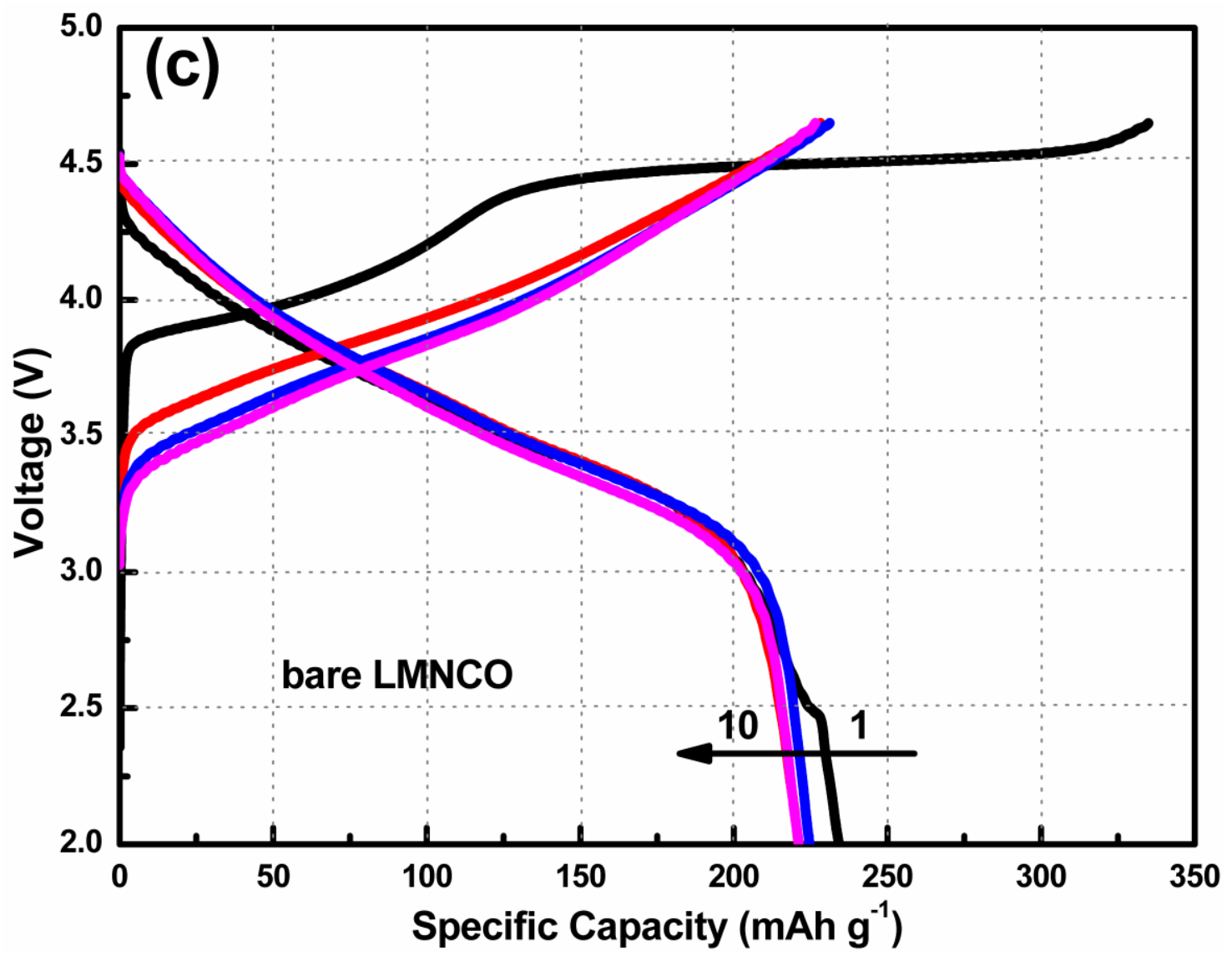




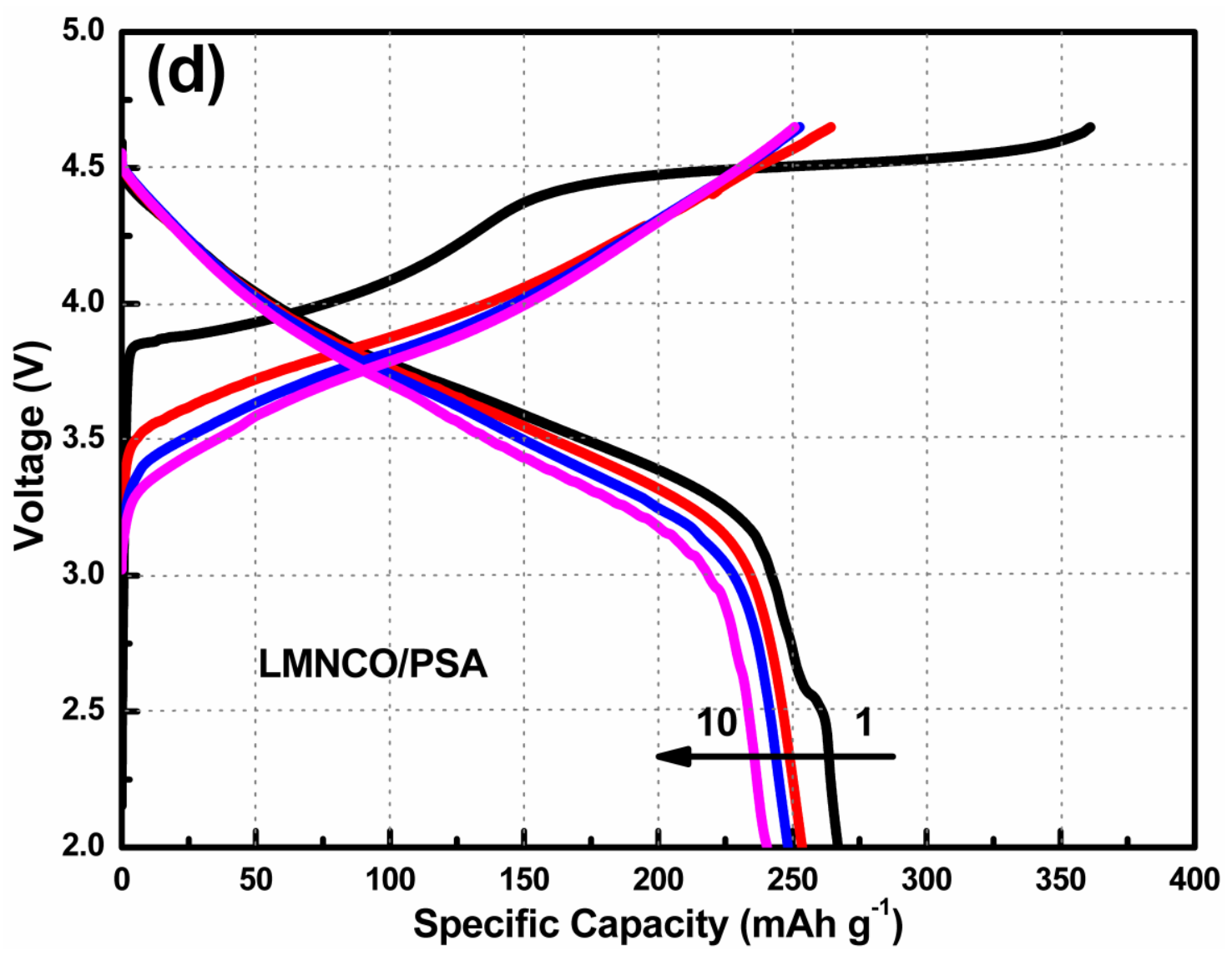




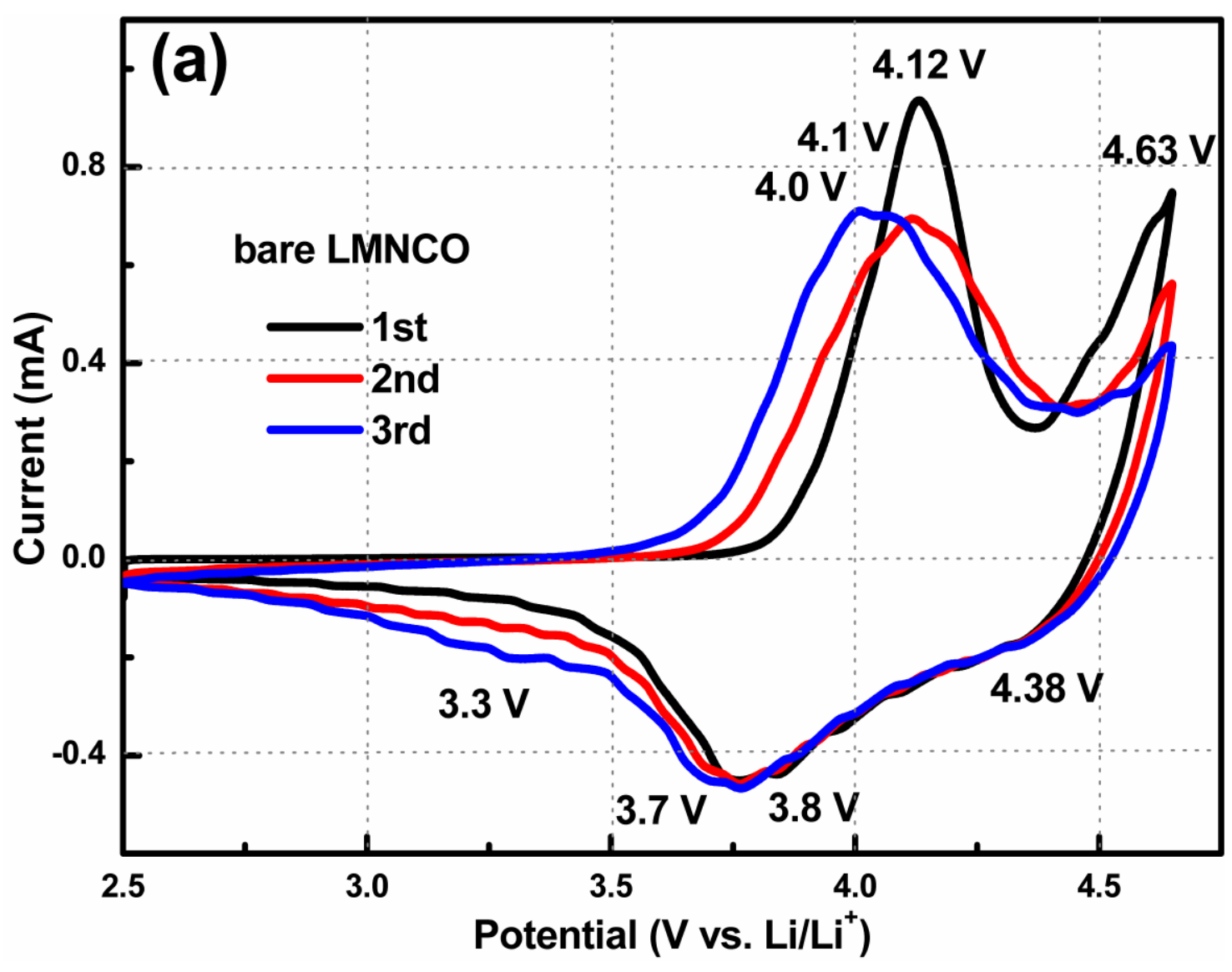




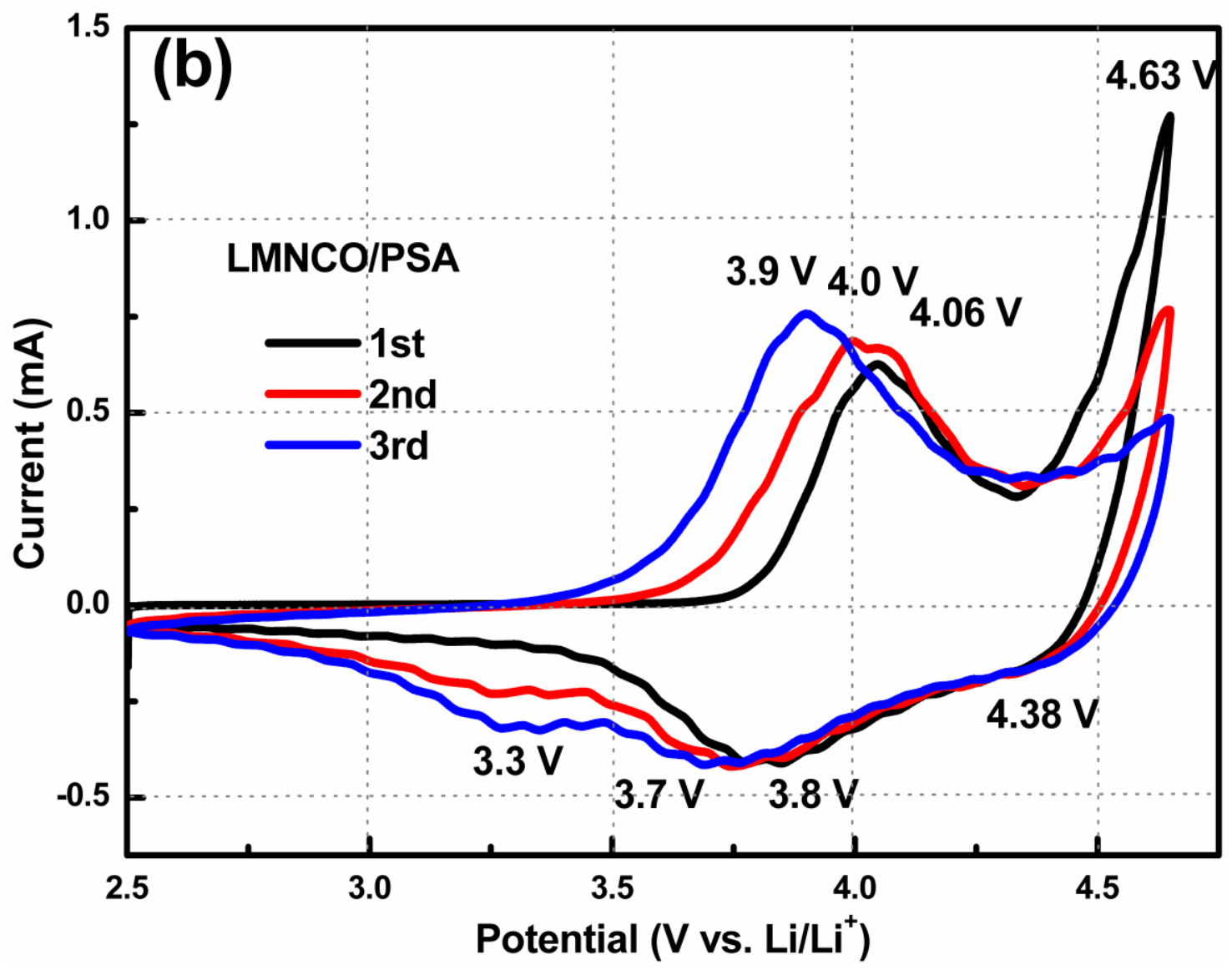




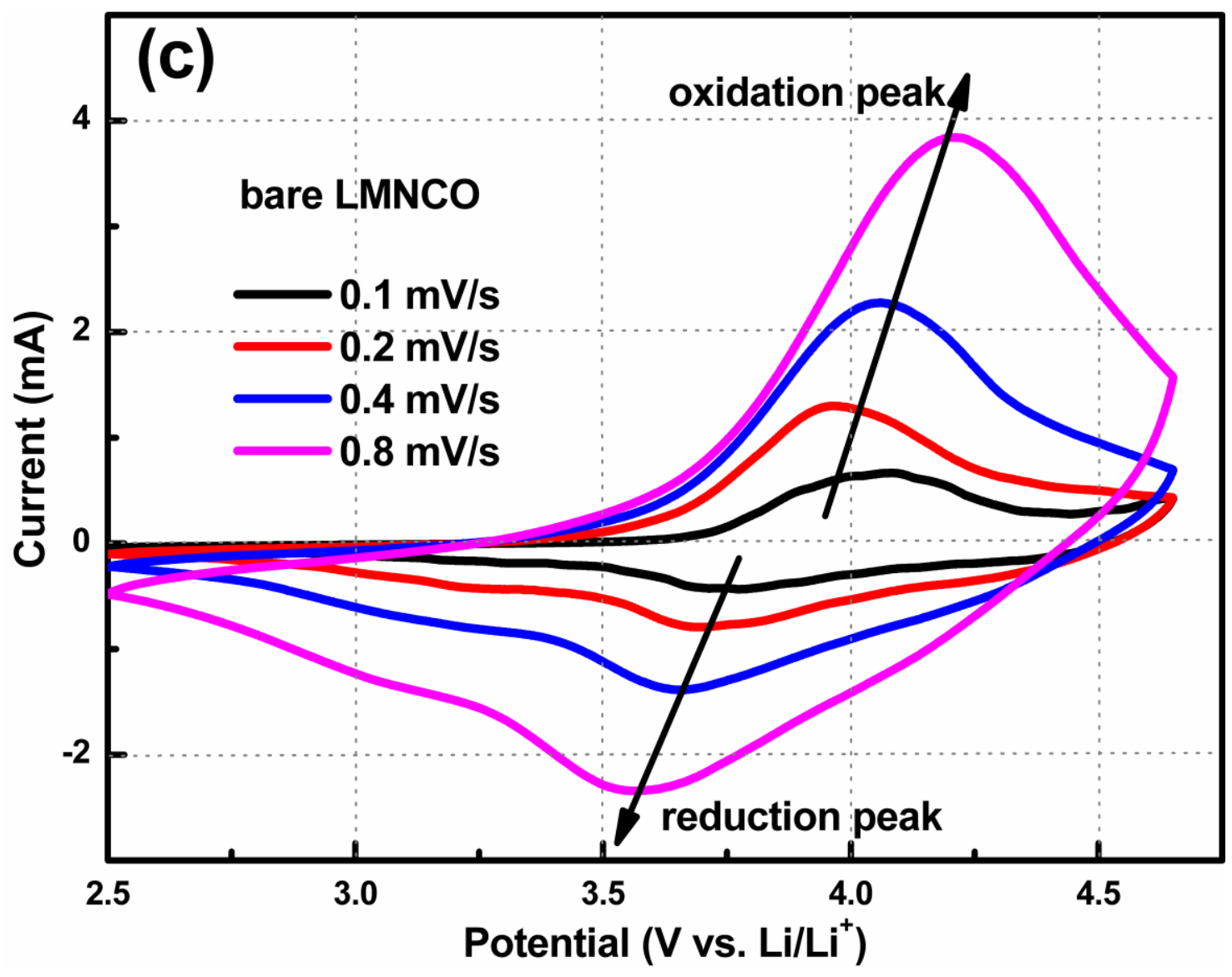




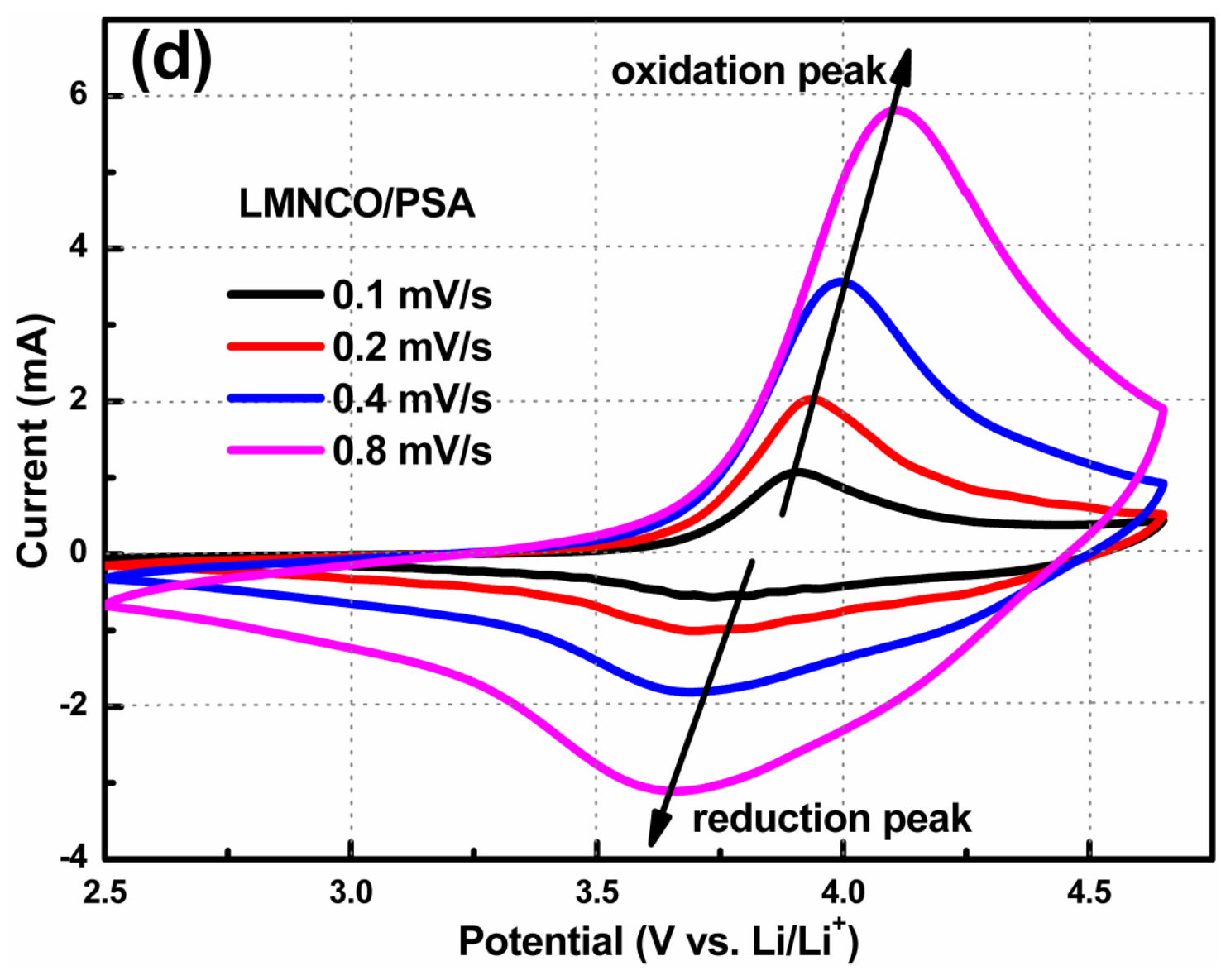




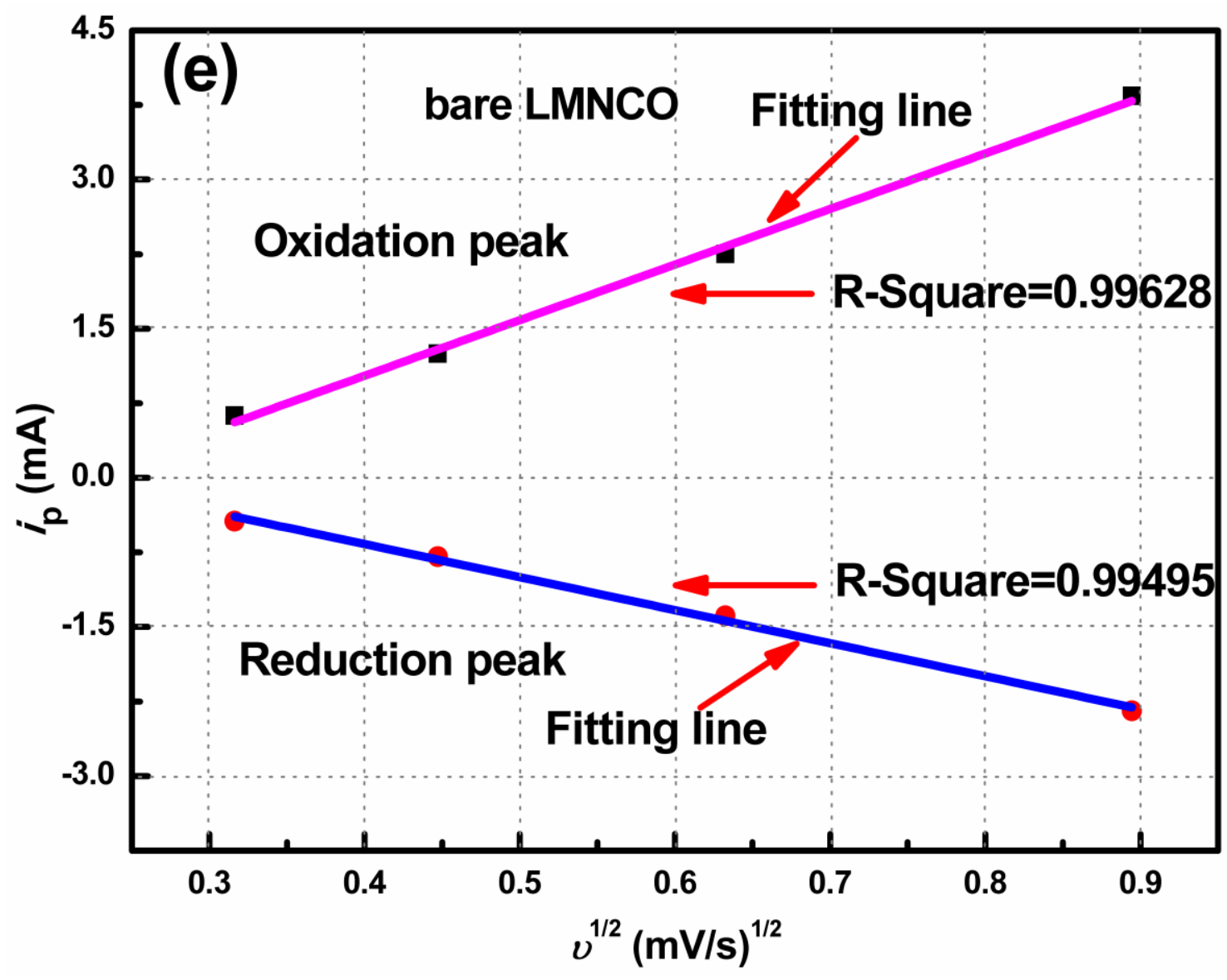




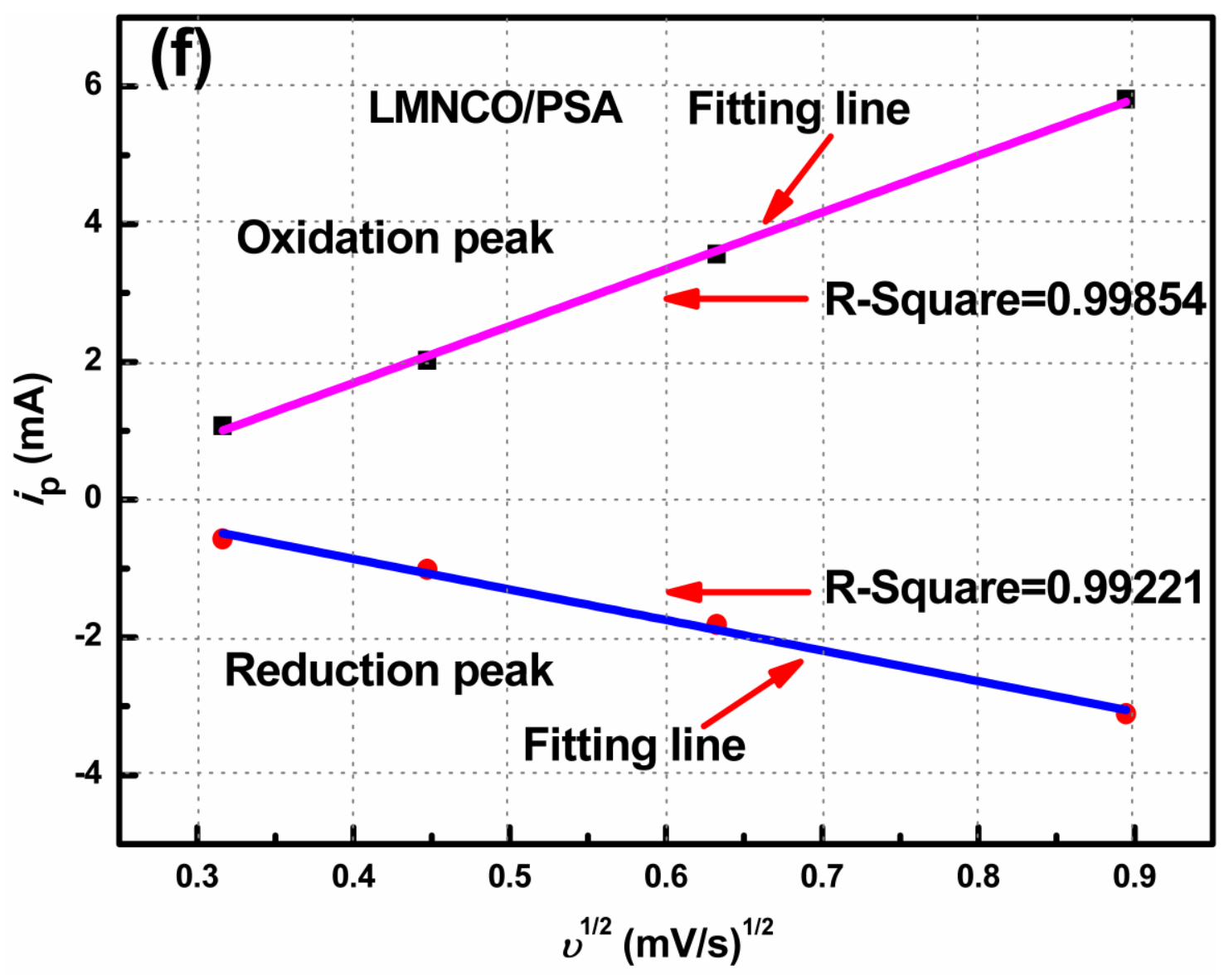




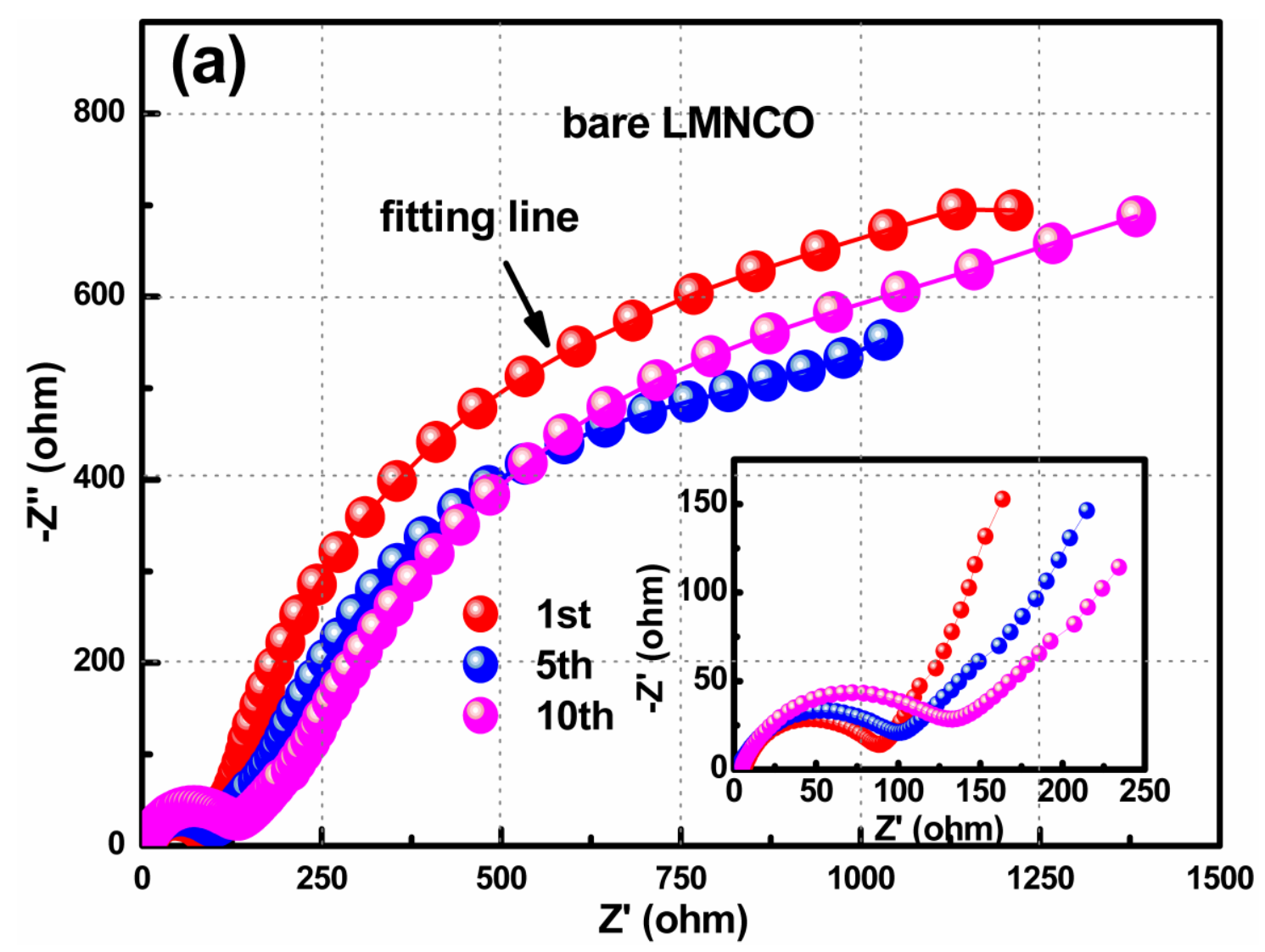




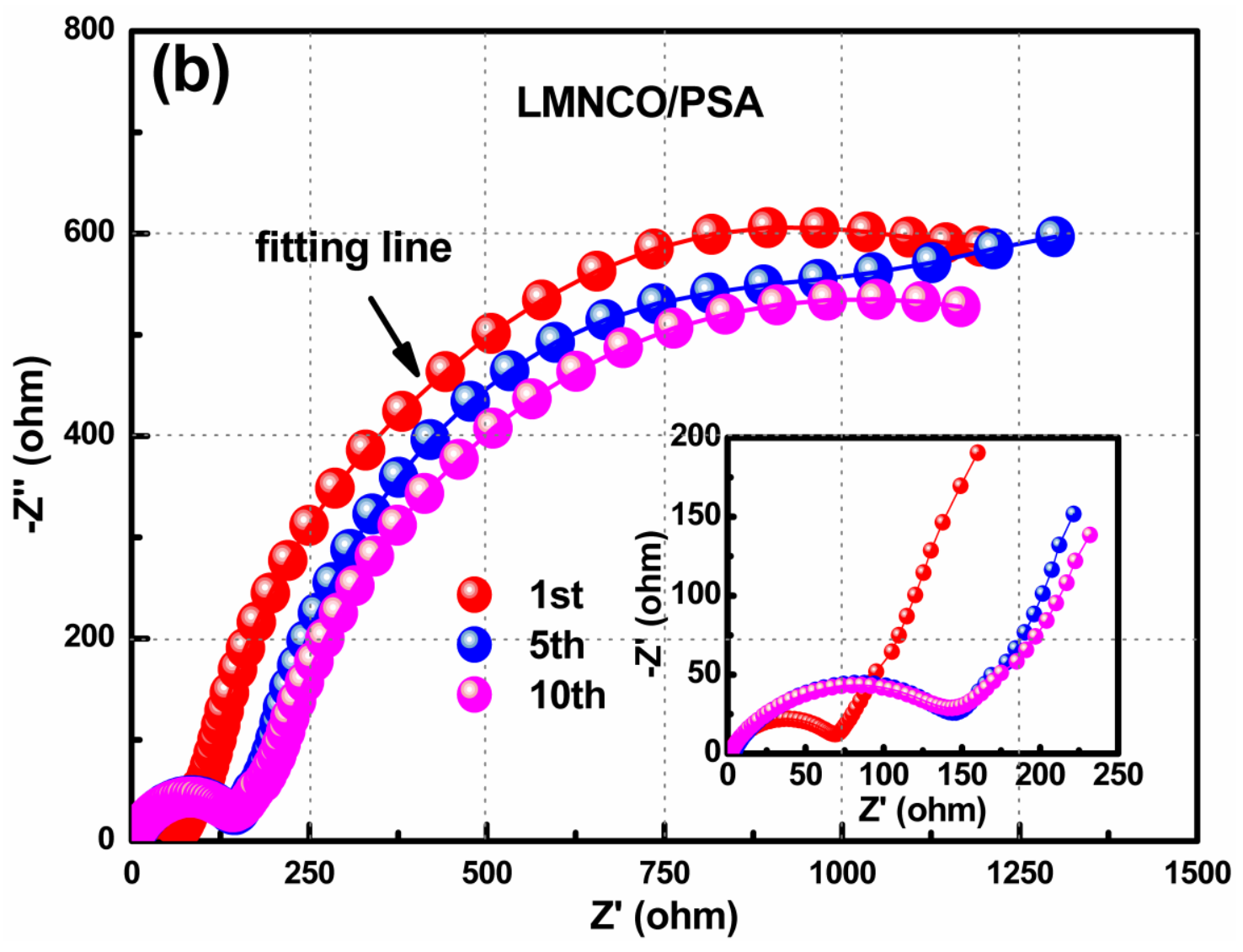




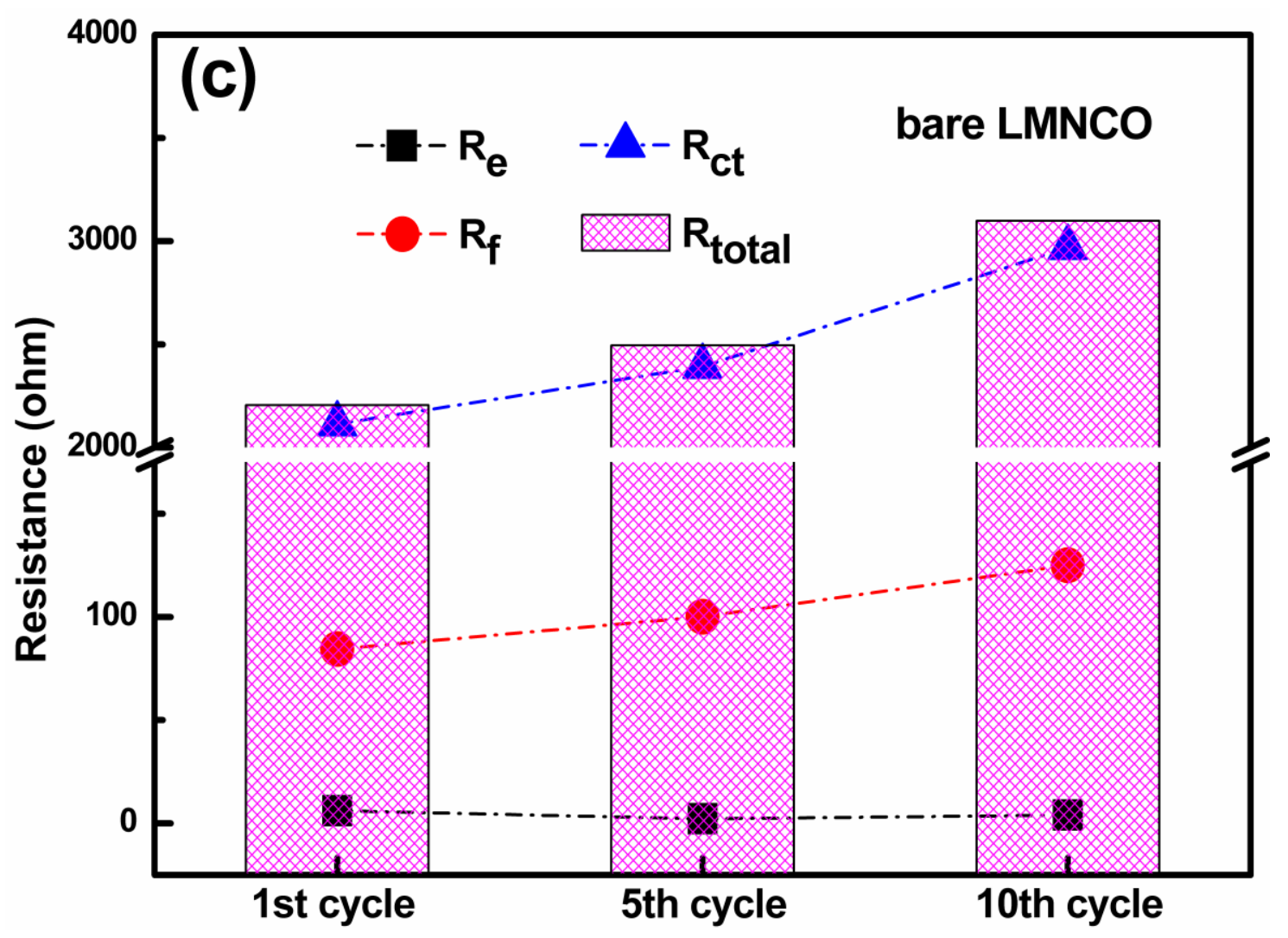




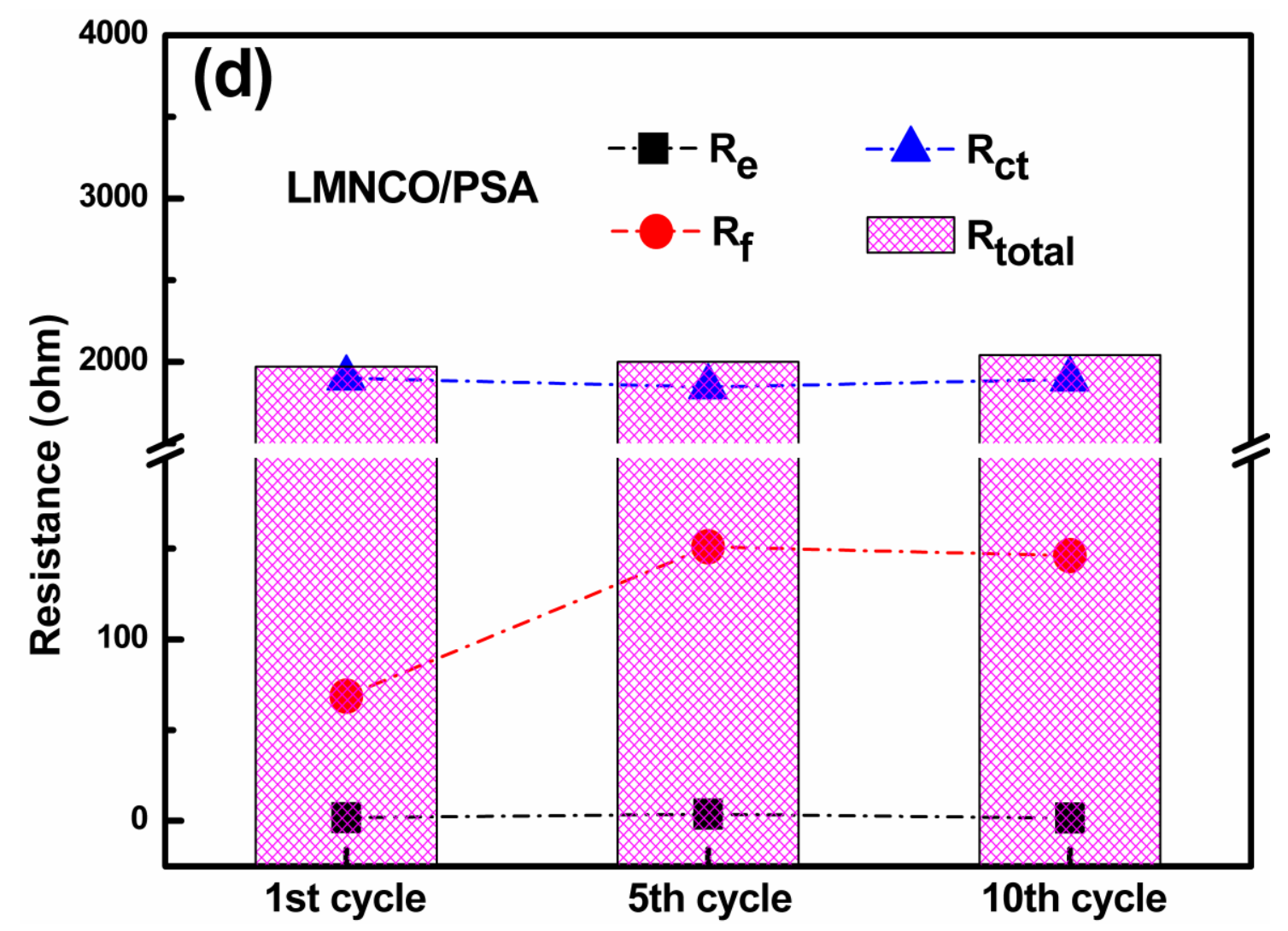


(e) 